\title{
The Tiny Drosophila Melanogaster for the Biggest Answers in Huntington's Disease
}

\author{
Abraham Rosas-Arellano ${ }^{1, *(1)}$, Argel Estrada-Mondragón 2 (1), Ricardo Piña ${ }^{3,4}$, \\ Carola A. Mantellero ${ }^{5}$ and Maite A. Castro ${ }^{6,7, * \text { (iD }}$ \\ 1 Unidad de Imagenología, Instituto de Fisiología Celular, Universidad Nacional Autónoma de México, \\ Ciudad de México 04510, Mexico \\ 2 Department of Clinical and Experimental Medicine, Linköping University, 58183 Linköping, Sweden; \\ argel.estrada@comunidad.unam.mx \\ 3 Laboratorio de Neurociencias, Departamento de Biología, Facultad de Química y Biología, Universidad de \\ Santiago de Chile, Santiago 9160000, Chile; ricardop@ug.uchile.cl \\ 4 Departamento de Ciencias Químicas y Biológicas, Universidad Bernardo O’Higgins, Santiago 8370993, Chile \\ 5 Facultad de Ciencias de la Salud, Universidad de Las Américas, Santiago 7500972, Chile; \\ carola.mantellero@usach.cl \\ 6 Instituto de Bioquímica y Microbiología, Facultad de Ciencias, Universidad Austral de Chile, \\ Valdivia 5090000, Chile \\ 7 Center for Interdisciplinary Studies on the Nervous System (CISNe), Universidad Austral de Chile, \\ Valdivia 5090000, Chile \\ * Correspondence: arosasar@email.ifc.unam.mx or a_rosasar@fisio.cinvestav.mx (A.R.-A.); \\ macastro@uach.cl (M.A.C.); Tel.: +52-555-622-5610 (A.R.-A.); +56-632-221-474 (M.A.C.); \\ Fax: +56-632-221-332 (M.A.C.)
}

Received: 2 July 2018; Accepted: 9 August 2018; Published: 14 August 2018

\begin{abstract}
The average life expectancy for humans has increased over the last years. However, the quality of the later stages of life is low and is considered a public health issue of global importance. Late adulthood and the transition into the later stage of life occasionally leads to neurodegenerative diseases that selectively affect different types of neurons and brain regions, producing motor dysfunctions, cognitive impairment, and psychiatric disorders that are progressive, irreversible, without remission periods, and incurable. Huntington's disease (HD) is a common neurodegenerative disorder. In the 25 years since the mutation of the huntingtin (HTT) gene was identified as the molecule responsible for this neural disorder, a variety of animal models, including the fruit fly, have been used to study the disease. Here, we review recent research that used Drosophila as an experimental tool for improving knowledge about the molecular and cellular mechanisms underpinning HD.
\end{abstract}

Keywords: neurodegenerative diseases; IT15; LOMARS; HTT; HD; huntingtin; mHTT; polyQ; polyglutamine disorders; chorea; neostriatum; fruit fly

\section{Introduction}

Living longer does not necessarily imply a healthy life. The increase in the elderly population is considered a human health phenomenon of global importance [1,2]. The average life expectancy, or the statistical measure of how long a person is likely to live based on demographic factors, has increased over the years. According to the World Health Organization (WHO), mankind has globally gained an additional 41 years of life over the past 200 years. It is estimated that individuals born in 2016 will live on average 72 years; 74.2 if female or 69.8 if male (available at www.who.int/gho/mortality_burden_ disease/life_tables/situation_trends_text/en/, accessed on 30 July 2018). However, the extended 
lifespan and the quality of life do not correlate. In 2015, the WHO estimated that a healthy life expectancy is up to 65 years, although not in all cases. At the end of adulthood (60-65 years) and to the elderly (66+ years), non-genetic (demographic and environmental) features and genetic vulnerability (dominant associated factor) are undisputed risk factors for the appearance of neurodegenerative diseases with sporadic global incidence. Age-dependent disorders have become a worldwide challenge and are receiving global attention because they are progressive, uninterrupted, irreversible, incurable, and unfortunately, lack effective treatment. Some of the most common neurodegenerative disorders are Alzheimer's, Parkinson's, Amyotropic Lateral Sclerosis, and HD [3].

Despite the fact that aging is a common shared feature of several neurodegenerative diseases, $\mathrm{HD}$ is a disorder with a variable age onset, characterized by a comparatively early age of disorder onset, resulting in a juvenile form of HD [3], detailed below. However, as in the other neurodegenerative diseases, the HD genetic factors are strongly related with risk factors, but only weakly associated with environmental or demographic factors [3].

A wide variety of animal models have been designed for the study of human neurodegenerative diseases, and they play a crucial role in studying the molecular, physiological, and behavioral principles that underlie each pathology. A high similarity between the human pathology and animal model phenotypes is an advantage, because the latter do not typically acquire the same genetic disease in a natural way. Twenty-five years ago, the abnormal polyglutamine repeat motif was identified as the HTT gene mutation responsible for HD [3]. Since then, several vertebrate and invertebrate models have allowed us to experimentally reproduce the genetic and molecular mechanisms that are characteristic of the human disease. Currently, genetic animal models are the most valuable tools that provide trustworthy information in order to understand the systemic and molecular dynamics, develop novel therapeutic strategies, and improve the quality of life of the affected patients and their offspring. Genetic HD animal models include transgenic, knock-in, and gene mutations in nonhuman primates, sheep, pig, mouse, zebrafish, and the fruit fly [4-10]; as well as diverse cell line models such as HdhQ7/111 and STHdhQ111 [11-13].

This review provides an update about the role and legacy of the fruit fly as an HD animal model without a polyglutamine (polyQ) motif in the corresponding homologous region of the N-terminal domain of its wild-type htt protein; as well as diverse genetically designed Drosophila models for the study of HD.

\section{Neurodegenerative Diseases}

As was mentioned above the majority of neurodegenerative diseases are produced by specific combinations of genetic predispositions, age onset, and environmental factors. Their effects are characterized by proteostasis dysfunction in vulnerable cells of different anatomical structures within the nervous system [14]. These disorders typically have a late onset and slow progression over time, with aging being an important factor of gradual cell damage build-up/death. Furthermore, such specific damage takes place in a defined population of neurons, based on the susceptibility of each disorder (i.e., dopaminergic substantia nigra pars compacta neurons for Parkinson's disease, projection neurons of the hippocampus and enthorhinal cortex for Alzheimer's disease, spinal motoneurons for Amyotropic lateral sclerosis, and striatal medium-sized spiny neurons (MSSNs) for HD [14]). Depending on the identity of the disease and its selective neuronal vulnerability in different stages, this will produce psychiatric conditions, cognitive disabilities, general motor impairment, dementia, and finally, death, all of which are hallmarks of neurodegenerative diseases [14,15].

Interestingly, inherent protein aggregates in a particular neurodegenerative disease are the result of the mutated version of otherwise ubiquitously expressed genes. Despite the fact that each neurodegenerative disease can affect a particular brain region, neural networks, or a specific subpopulation of neural cells; the corresponding subcellular targets that are damaged, such as mitochondria and endoplasmic reticulum (ER); and the related intracellular processes, including autophagy, proteostasis, and ER stress, are common features in several neurodegenerative disorders 
like Alzheimer's, Parkinson's, and HD [15]. These three pathologies have their selective mutant protein aggregates, namely: Beta-amyloid and tau for Alzheimer's disease, alpha-synuclein for Parkinson's disease, and mutant HTT for HD [3,15-17].

\section{Wild-Type and Mutant Huntingtin}

The huntingtin gene, abbreviated as HTT in Homo sapiens (Human Genome Organization [HUGO], Gene Nomenclature Committee), is also known as IT15 (interesting transcript 15), HD, and LOMARS (Lopes-Maciel-Rodan Syndrome). HTT is a gene with a large locus, spanning $180 \mathrm{~kb}$ and consisting of 67 exons. It is expressed as two alternatively polyadenylated forms; the first is a larger transcript $(13.7 \mathrm{~kb})$ than the second $(10.3 \mathrm{~kb})$. Throughout life, the larger HTT transcript is constitutively expressed in the nervous system, whereas the smaller transcript is expressed in other organs (NCBI, Gene ID: 3064). HTT is translated into a multifunctional protein also called HTT, which is required from early development to later stages of life. HTT is involved in vesicular transport, endocytosis, autophagy, and transcriptional regulation [18-20]. HTT, alternatively called Huntington's disease protein or, simply, HD protein (UniProtKB-ID: P42858), in vertebrates, is a highly conserved soluble $348 \mathrm{kDa}$ protein [21] (Figure 1A). There are few similarities in the sequence between humans and other species, which also occurs with the orthologous gene of the fruit fly. The HTT gene is located in (data are provided with the official abbreviation of each species) chromosome 1 in zebra fish ( $h t t$, ID: 30214), 4 in human (HTT, ID: 3064), 5 in mouse (Htt, ID: 15194), 6 in cattle (HTT, ID: 615059), 14 in rat (Htt, ID: 29424), 17 in Japanese pufferfish ( $h t t$, ID: 101065600), and 3R in fruit fly ( $h t t$, ID: 43392). A full analysis of the primary protein sequence alignment of these representative species is illustrated in Supplementary Figure S1. The HTT protein is related to several cellular functions, such as embryonic development (lethal during the development of knockout mice), intracellular transport of molecules (such as vesicle trafficking), apoptosis (prevents caspase activation), and transcription regulation (in brain-derived neurotrophic factor expression) [22-25].

In humans, an important and distinctive characteristic of HTT consists of a short and repeated sequence of glutamines, known as the polyQ motif, located at the $\mathrm{N}$-terminal domain. The polyQ domain is encoded by a cytosine-adenine-guanine (CAG) triplet repeat in the first exon of the gene (Figure 1B). The total polyQ length is longest in humans and is not conserved amongst different species (Figure 1C). Interestingly, the number of glutamines decreases between the lineages that were separated early in evolution [21]. The polyQ sequence appeared in the HTT protein for the first time in the evolutionary timeline in fish. Its physiological function is related to the recognition mechanism of transcription factors and other protein-protein interactions [23].

Altered expandable repeats of the CAG trinucleotide encode for glutamine, resulting in abnormal polyQ repeats, also known as the polyglutamine tract. These abnormal polyQ repeats are the hallmark of incurable, hereditary, and degenerative disorders called polyQ diseases, which include spinal and bulbar muscular atrophy (35 - 38 CAG repeat size), dentatorubropallidoluysian atrophy (49 - 88 CAG repeat size), and various spinocerebellar ataxias (SCA1, 39 - 82 CAG repeat; SCA2, 34 - 64 CAG repeat; SCA3, 60 - 84 CAG repeat; SCA7, CAG repeat 34 - 306) [26-28]. Unaffected people have a range between 6 - 35 CAG repeats, with $99 \%$ of such individuals having <30 repeats; however, those with HD have 36 - 121 CAG repeats [29-31]. Expandable CAG repeats can increase via inheritance, raising the probability of longer triplet repeats and early HD onset in successive generations. It is also assumed that the repeat expansion mechanism occurs during DNA replication. The following factors have been suggested: (1) DNA strand slippage during replication; (2) looping of one or several repeats in the newly synthesized DNA strand; and (3) unusual structural characteristics, such as hairpin-like structures that give rise to slip-outs that are folded into these DNA structures, being the Okazaki initiation zone, a region that could facilitate the unusual secondary structure [32]. Accumulation of defective HTT proteins induces its stacking in the nucleus, producing internal anomalous functions in addition to mitochondrial dysfunction and impairments commonly found in the proteasome system, in axonal transport, and in calcium homeostasis [33-35]. 
A

\begin{tabular}{|c|c|c|c|c|c|c|c|}
\hline Drosophila & 100 & 23.42 & 23.99 & 23.69 & 2361 & 23.45 & 23.25 \\
\hline Takifugu & & 100 & 81.52 & 71.01 & 72.59 & 71.60 & 71.52 \\
\hline Danio & & & 100 & 71.72 & 73.46 & 72.56 & 72.52 \\
\hline Bos & & & & 100 & 89.43 & 87.37 & 87.11 \\
\hline Homo & & & & & 100 & 91.18 & 91.08 \\
\hline Rattus & & & & & (3 & 100 & 97.69 \\
\hline Mus & & & & & & & 100 \\
\hline
\end{tabular}

B
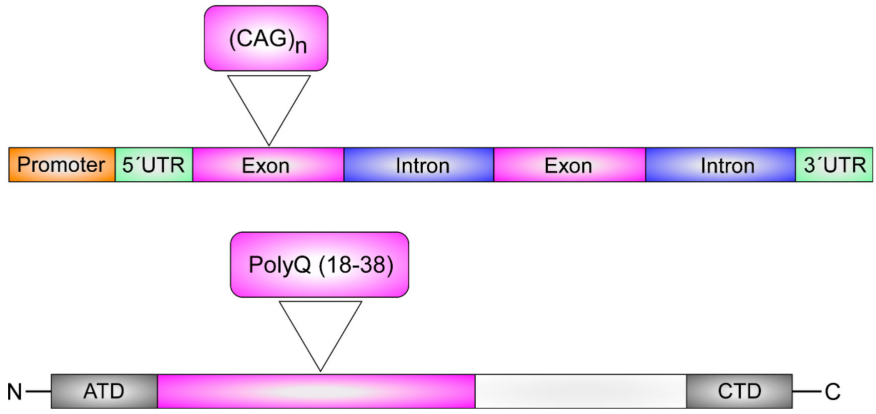

C

\begin{tabular}{|c|c|}
\hline Drosophila & MATMEKLMKAFFSLKSFOOOOG- \\
\hline Takifugu & MATMEKLMKAFESLKSFQQQQG-- \\
\hline Danio & MATMEKLMKAFESLKSFQQQQG------.. \\
\hline Bos & MATLEKLMKAFESLKSFQQQQQQQQQQQQ------QQQQPPP---PPQPPQPPQPPPQAQ- \\
\hline Homo & MATLEKLMKAFESLKSF $Q Q Q Q Q Q Q Q Q Q Q Q Q Q Q Q Q Q Q Q P P P P P P P P P P P Q L P Q P P P Q A Q P$ \\
\hline Rattus & MATLEKLMKAFESLKSF $Q Q Q Q Q Q Q Q P--------->P P Q A P P P P P P P P P Q P P Q P P P Q G Q-$ \\
\hline Mus & MATLEKLMKAFESLKSFQQQQ-QQQP---------PPQAPPPPPPPPPQPPQPPPQGQ- \\
\hline Drosophila & $------------M D K S R S S A Y D K F V G F V E Q L R N T E C S Q K Q K I T C F Q Q I A E C I M S P S L A G$ \\
\hline Takifugu & - - \\
\hline Danio & ---1 \\
\hline Bos & $----P P P Q P P P P P P P L G P A A A-E E P--L H R P K K E L S A T K K D R V H H C L T I C E N I V A Q S L R N$ \\
\hline Homo & LLPQPQPPPPPPPPPPGPAVA-EEP--LHRPKKELSATKKDRVNHCLTICENIVAQSVRN \\
\hline Rattus & ------- PPP-PPPLPGPA-EEP--LHRPKKELSATKKDRVNHCLTICENIVAQSLRN \\
\hline Mus & -------- PPPPPPPLPGPA-EEP--LHRPKKELSATKKDRVNHCLTICENIVAQSLRN \\
\hline
\end{tabular}

Figure 1. Multiple sequence analysis of huntingtin protein using Clustal Omega. (A) Percent identity matrix of the HTT proteins of several species (Takifugu rubipres in orange; Danio rerio in green; Bos taurus in cyan; Rattus norvegicus in purple; Mus musculus in blue aqua color); the homologies between Homo sapiens (blue) and Drosophila melanogaster (yellow) are highlihted. (B) Linearized HTT gene and protein showing the CAG location and polyQ region. (C) Multiple sequence analysis of polyQ and polyP repeats of HTT protein. All figures using protein sequences of mammalian (Homo sapiens, UniProtKB-P42858; Mus musculus, UniProtKB-P42859; Bos taurus, UniProtKB-E1B8E7; and Rattus norvegicus, UniProtKB-G3V9P7), fish (Danio rerio, UniProtKB-O42269, and Takifugu rubripes UniProtKB-P51112), and fruit fly (Drosophila melanogaster, UniProtKB-Q9V3N4) species. An asterisk $\left(^{*}\right)$ indicates positions which have a single, fully conserved residue. A colon (:) indicates conservation between groups of strongly similar properties. A period (.) indicates conservation between groups of weakly similar properties. 


\section{Huntington's Disease}

In the mid-19th century, George Huntington described this neurodegenerative disorder for the first time [36] as a hereditary, progressive illness characterized by clonic spasms and a lack of remission periods. Initially, HD was known as Huntington's chorea, St. Vitus' dance (a derogatory term), chorea of the aged, choreic dementia, dementia choreica, Osler's preference, and chronic progressive chorea. It was not until the late 1960s that it received the name of HD [37].

$\mathrm{HD}$ is considered an infrequent neurological disorder with devastating consequences on quality of life. It affects women and men alike and the onset is between the ages of 30 and 55 years old. Moreover, a juvenile form of HD affects children and teenagers (cases with CAG repeats of 55 or greater, instead of over 40 in adult-onset HD). The prevalence and incidence rate of HD worldwide is unclear. A poor case ascertainment and inadequate diagnosis contribute to this important gap in our knowledge. Data published in 2016 by Rawlins and colleagues [38] suggested a prevalence in principal regions in the world as follows: (data are an average prevalence per 100,000 [95\% confidence indexes \{CIs\}] and trend [percent] by decade, respectively) Asia $0.40(0.36-0.44), 8.9(-2.24$ to +23.8$)$; Central and Eastern Europe 2.17 (1.95-2.41), 15.4 (2.70 to +38.6); North America 7.33 (6.94-7.74), 20.1 (+18.1 to 22.1); Oceania 5.63 (5.61-6.25), 15.4 (+11.6 to +19.3); United Kingdom 6.68 (6.40-6.97), $15.5(+11.3$ to +18.0); and Western Europe 3.60 (3.50-3.69), 16.5 (+14.9 to +18.6).

As mentioned above, HD is an adult-onset, autosomal dominant polyQ disease that produces three major imbalances, namely: (A) Motor dysfunction, such as muscle spasms, uncontrollable jerking movements, rigidity, and speech problems. (B) Cognitive deficits, namely learning difficulties, difficulties in areas of planning and prioritizing, and impairments in spatial perception. (C) Psychiatric comorbid disorders including depression, personality changes, anxiety, delirium, mania, and dementia. In sum, these imbalances constitute the pathognomonic features of HD [39,40]. Another emerging distinguishing characteristic of HD is a peculiar signal at the cytological level. Mutant HTT carries a dominant toxic property that results in major cell damage and death in the basal ganglia. Specifically, this toxicity causes large neostriatal atrophy in a distinctive population of neostriatal projection neurons, known as MSSNs, expressing dopamine D2 receptors/encephalin-containing neurons [41-47]. Correspondingly, HD induces clear alterations at the neurochemical and receptor levels in the neostriatum $[45,48-55]$.

\section{Neostriatum and Central Complex as Homologous Neuroanatomical Structures}

The anatomical nomenclature of the neostriatum is given to the collective conjunction of the caudate and putamen structures of the brain, sometimes called corpus striatum or, simply, striatum; however, the term striatum is also used to refer to the anatomical complex formed by the caudate and lentiform nucleus (formed by the putamen and globus pallidus). In accordance with the former nomenclature, we used the neuroanatomical term neostriatum in this review to refer to the caudate and putamen, as it has been used previously [56,57]. The neostriatum consists of three main regions, dorsal, ventral, and amygdaline. All regions are composed of matrix and striosomes (also known as patches) [58]. The neostriatum is the first to relay information between the cerebral cortex input and basal ganglia output, and it has been associated with motor control, learning, memory, and the emotional part of movement (amygdaline region) [59-61]. Neostriatum cytology is formed by two general cell groups, spiny or projection neurons, and aspiny or interneurons. The former group is also known as medium spiny neurons or MSSNs. This kind of neurons has cellular bodies between 10 and $20 \mu \mathrm{m}$ in diameter, and dendritic trees with abundant spines and a dendritic extension of up to $500 \mu \mathrm{m}$ in diameter. All MSSNs are gamma-aminobutyric acid (GABA) -containing neurons and represent the most abundant neostriatal neuron type, making up $95 \%$ of the total neuronal population [56]. MSSNs synthetize neuropeptides differentially in two selective populations, one corresponds to substance P projection neurons, in addition to the dopamine D1 receptor (called the direct pathway), and the other corresponds to enkephalin projection neurons, which express the dopamine D2 receptor (called the indirect pathway) [62,63]. Functionally, the enkephalin/D2 neostriatal inhibitory neurons 
have opposite effects (compared to substance P/D1 excitatory neurons) on the neural activity of their downstream synaptic targets [64] and are involved in the facilitation of planning movements of the trunk and limbs, and in the inhibition of involuntary movements [64,65].

Vertebrate basal ganglia and the arthropod central complex derive from embryonic basal forebrain lineages that are specified by an evolutionary conserved genetic program leading to interconnected neuropils and nuclei that populate the midline of the forebrain-midbrain boundary region; in addition, gene expression patterns are specific to the region of the developing brain, corresponding to that of the vertebrates. The Dlx1/2, Tlx, Nkx2.1, Pax6, Emx2, Gsh1/2, and Lhx6/7 genes play essential roles in the development and specification of the neostriatum, and have homologs in Drosophila FGF8, SHH, BMP, Otx2, Dlx1/2, Tlx, Nkx2.1, Pax6, Emx2, Gsh1/2, En1/2, and Pitx2 [66]. Moreover, the region-specific gene expression patterns in the developing brain correspond to those in vertebrates. Therefore, the central complex of arthropods and the vertebrate basal ganglia are homologous brain structures that both share topography and embryological derivation, as well as functionality and gene expression $[66,67]$. The central complex structure is highly conserved across the insect species [68]. Functionally, the central complex of Drosophila is involved in start-stop and turning locomotor activity, walking activity, speed, leg coordination, restlessness, flight behavior, control and fine tuning of behavior [69-71]. This neuroanatomical structure is strongly related to the integration of data from the two brain hemispheres, consisting of the following four interconnecting midline neuropils: protocerebral bridge, fan-shape body, ellipsoid body, and paired noduli, where at least 15 neuronal lineages have been identified [71-73]. The majority of these neuron classes have been categorized as large-field and small-field neurons. The former group typically arborize within one or more tangential layers of the central complex, and they form networks with one or more accessory structures outside of the central complex; whereas the latter group interconnect neuropils of the central complex and a subpopulation project into other brain regions [68]. Interconnections between neuropils are restricted; fan-shape body neurons connect with specific regions of noduli, while the protocerebral bridge make its particular connection with the noduli through the ellipsoid body [74]. Structural hallmarks of the neostriatum include the neuronal arrangement in the striosomes and matrisomes, whereas in the fly central complex, neuropils display several arrangements, namely: the protocerebral bridge is divided into sectors or segments, the fan-shaped body compromises of an arrangement of successive synaptic layers intersected by repeated arrangement modules, the ellipsoid body is subdivided into three axes called rings, whereas noduli have several subdomains named dorsal, medial, and ventral compartments, suggesting a high degree of regional specialization into the central complex [74]. In vertebrates, the D1 pathway has a net positive effect on the basal ganglia output, while the D2 pathway has a negative effect. In Drosophila, clusters of dopamine-containing D1 neurons have specific projection patterns, and some clusters are associated with mushroom bodies, the central complex, fan-shaped body, ellipsoid body, and lateral accessory lobes. Of course, all of these similarities do not exclude the possibility that some of these pathways may retain parallel functions or compensatory co-adapted circuits. The multiple commonalities mentioned here only demonstrate the deep homology of the arthropod central complex and vertebrate basal ganglia. Functionally the central nervous system (CNS) specific depletion of dopamine in Drosophila results in reduced activity, locomotor deficits, extended sleep time, and defects in the aversive olfactory memory formation, suggesting that arousal and choice require normal dopamine levels. The perturbation of dopaminergic pathway activity, or its modulatory output interferes with the corresponding behavioral actions, common in age-related degeneration of the dopaminergic clusters, and typical of HD. As in the neostriatum, the central complex displays a strong GABA neurotransmitter and receptor expression, at least in the ellipsoid body neuropil [66,67]. 


\section{The Drosophila Huntingtin}

Unlike humans, Drosophila htt does not express an expanded polyQ sequence in its amino terminal domain. Nevertheless, Drosophila and human proteins share around of $49 \%$ positive homology and $27 \%$ identity. Therefore, the considerable sequence conservation between the two species predicts a common folding for both proteins. Human HTT is a large $348 \mathrm{kDa}$ protein and was recently studied by cryo-electron microscopy at an overall resolution of $4 \AA$. It consists of three domains, two of which are the $\mathrm{N}$-terminal and C-terminal domains containing multiple tandem repeats of a structural motif composed of two alpha helices linked by a short loop [20]. The tandem sequence was identified in the following four archetypical proteins: the representative Huntingtin, elongation factor 3 (EF3), protein phosphatase 2A (PP2A), and yeast kinase TOR1, collectively known as HEAT [75]. The HEAT repeats are linked by a third and smaller bridge domain. The N-terminal HEAT repeat forms an $\alpha$-solenoid, comprising of 21 HEAT repeats arranged as a one and a half-turn right-handed superhelix. The C-terminal HEAT repeat comprises of 12 HEAT repeats forming an elliptical ring. Many recent structural studies have focused on the N-terminal fragment corresponding to the first exon of the HTT gene, where the polyQ tract is located, and which remains largely unknown [20]. Figure 2 contains a model that represents a possible mechanism of how this domain interacts with the rest of the N-terminal huntingtin protein in humans, not in Drosophila. Interestingly, the htt protein sequence is highly conserved between the Drosophila species, suggesting a common biological function in the fruit fly [76,77], and a key tool to study the main functions of this protein in this animal model. Similar to vertebrates, htt protein is transported bi-directionally in Drosophila's axons, where it is associated with several proteins that receive the name of huntingtin associate proteins (HAP), with HAP40 being a key regulator of endocytosis, a critical factor for HD development in humans [78]. No HAP40 homologue appears to be present in Drosophila, suggesting that these two proteins may have co-evolved in vertebrates, and their interactions could be important for the appearance of HD in humans [20]. In any case, some other huntingtin interacting proteins are dynactin, dynein intermediate chain, and kinesin $1[22,79,80]$, which are still under extensive research. 
A

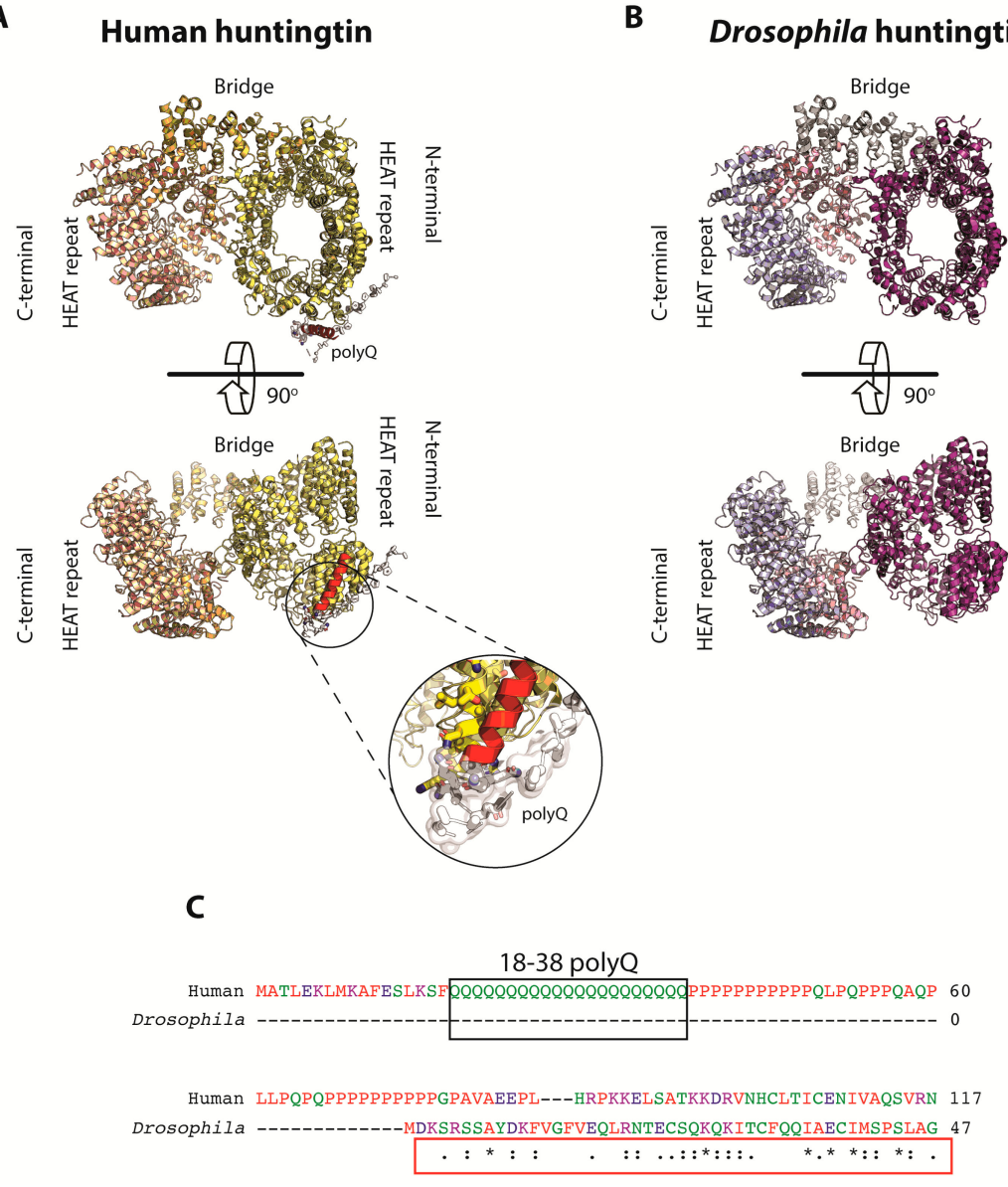

Figure 2. Comparison between Homo sapiens and Drosophila melanogaster huntingtin proteins. (A) Architecture of Homo sapiens HTT with its different domains in two different planes, with a rotation of 90 degrees on the $\mathrm{X}$-axis. The $\mathrm{N}$-terminal domain begins with an $\alpha$-helix continued for a stretch of polyglutamines/polyprolines not present in the homologous version of this protein in Drosophila melanogaster. Such a domain is zoomed in to highlight its key role and interaction with the rest of the protein for the development of HD. HEAT repeats domains are represented by C-terminal (ochre), bridge (yellow) and N-terminal (pale yellow). (B) Architecture of Drosophila melanogaster htt showing its different domains in two different planes, represented in the same way as the Homo sapiens homologous version. HEAT repeats domains are represented by C-terminal (purple blue), bridge (purple violet) and $\mathrm{N}$-terminal (purple deep). (C) Alignment of the first part of the N-terminal domain of the Homo sapiens and Drosophila melanogaster huntingtin protein sequences, identifying the polyglutamine stretch as relevant for HD development in the Homo sapiens sequence but not in the Drosophila melanogaster sequence. The figure was created using the Protein Data Bank entries 3io4 and 6ez8 [20,81]. An asterisk (*) indicates positions which have a single, fully conserved residue. A colon (:) indicates conservation between groups of strongly similar properties. A period (.) indicates conservation between groups of weakly similar properties.

\section{The Legacy of Fly Models in HD}

\subsection{Drosophila melanogaster as an Animal Model}

Drosophila is a well-known model organism that plays a critical role in biological sciences; moreover, the fruit fly has been recognized as an indispensable tool in neurobiological, biomedical, and developmental biology research [82]. Despite apparent differences between these organisms and vertebrates, several molecular mechanisms are highly conserved across evolution, such as the body axes pattern, wiring of a complex nervous system, organogenesis, and control of cell proliferation $[83,84]$. 
Exceptionally, many biological processes are common between fruit flies and humans, and these intrinsic similarities have allowed us to elucidate crucial mechanisms such as inheritance patterns [85], genetic mutations [86], genetic control of development [87], innate immunity control [88], and biological rhythms [89]. These and other research findings highlight Drosophila as an indispensable animal model.

Humans and fruit flies displayed an evolutionary divergence of about 783 million years. A total of $14.9 \%$ of human genes and $46 \%$ of Drosophila genes have orthologs to one or more fly and human genes, respectively [90]. Powerful genetic techniques have been used in Drosophila research and have proven useful for producing mutant models for the study of molecular processes (i.e., for biometal kinetics and mechanisms using chimeric proteins) [46,91,92], and to analyze human diseases; over five hundred Drosophila genes have been clearly related to human disease genes, including polyQ disorders $[26,84]$. The fruit fly is considered an exceptional model system to study neurodegenerative diseases [93]. Transgenic fruit flies can reproduce several characteristics of these disorders, including reduced longevity; late onset; motor syndromes; gradual accumulation of aggregates in neurons, axons, and cytoplasm; and consequently, neurodegeneration itself. In HD, Drosophila has been used as an animal model to report whether the distinct pathogenic elements of polyQ disorders are due to altered protein behavior, or to an inherent cytotoxic influence by enlarged polyQ chains [79,93].

In many of the cases referred to herein, the Drosophila model system has shown a plethora of molecular aspects that have enlightened us with fundamental elements to better understand the appearance and progression of the disease. Many of these studies performed on the Drosophila model can be directly extrapolated to the development of human HD, and they promise to be a valuable source of knowledge to palliate the disease by assisting in the development of new and effective drugs. These drugs should be able to mitigate, delay the manifestation, and eventually revert and cure this serious health problem that is already affecting tens of thousands of people around the world. In this section, we will discuss several studies that are key to understanding this devastating disease; we will also use the abbreviation " $h t t$ ", instead of "HTT" (human huntingtin gene), to properly refer to and distinguish the Drosophila huntingtin gene and htt to differentiate its protein counterpart.

\subsection{Transgenic Flies for the Study of HD Initiation and Development}

A critical phase in HD pathogenesis is the cleavage of the full-length htt protein, which releases $\mathrm{N}$-terminal fragments of variable sizes and has a polyQ stretch that becomes cytotoxic in neuronal cells [94]. A recent study using a transgenic fly model (FL-HTTQ200) (for HD fly models' information, see Table 1) expressing the tobacco etch virus (TEV) showed the proteolytic consequences of full-length htt. N-terminal hydrolysis disrupts intramolecular interactions within htt, causing toxicity in flies. In addition to canonical pathogenic $\mathrm{N}$-terminal fragments, $\mathrm{C}$-terminal fragments can also be created by double proteolysis, and both the N-terminal and C-terminal byproducts induce greater toxicity via dilation of the ER and increased ER stress, thus impairing dynamin 1 protein activity and leading to cell death. Upon TEV induction, the double proteolysis of htt was significantly more toxic to flies than any other combination. Thus, $\mathrm{N}$-terminal and C-terminal metabolites of htt proteolysis are toxic in vivo [95].

When studying HD development, it was found that one of the earliest signs of neurological deterioration in the progression of this disorder is the sleep cycle. Sleep disruptions are common in pre-symptomatic patients and early HD bearers, and include altered sleep architecture, interrupted sleep-wake behavior or sleeplessness with reduced rapid eye movement sleep [REM], increased sleep latency, and increased nocturnal activity [96]. Sleep defects may reveal the initial pathological development of HD; flies expressing the huntingtin mutant version exhibit decreased nighttime sleep in early adulthood. In this regard, the Drosophila model system has been critical for the molecular and genetic dissection of the circadian clock, and has emerged as a powerful system for understanding sleep regulation [96]. A study was conducted using the transgenic HD fly model expressing the full-length mutant htt protein ( $p$ upstream activating sequence [UAS]-Htt128Q), and three different genomic inserts of an $\mathrm{N}$-terminally truncated mutant $h t t$ transgene to identify disturbances during sleep-wake behavior. 
In general, the elevation of cyclic adenosine monophosphate (cAMP), protein kinase A (PKA), and cAMP response element binding (CREB) activity decreases sleep in flies. Genetic diminution of PKA signaling suppresses HD-related larval lethality and reverses sleep and activity phenotypes, complementing the neuronal mutant $h t t$ expression. In general, the PKA reduction prolongs the median lifespan of the HD model flies [96]. Two different methods were used to genetically alter PKA levels, namely: (1) by means of upstream activating sequence promoter (UAS-driven) transgenes that express ribonucleic acid interference ( $R N A i$ ) directed against the catalytic subunits of PKA, knocking down its activity; or (2) by the overexpression of a regulatory subunit. Both methods suppress lethality because of the directionality of the altered PKA activity, and not the off-target effects of RNAi [97]. Decreasing PKA signaling partially or fully suppresses all of these phenotypes, suggesting a relationship between aberrant signaling, sleep, and early disease progression. The early onset of these sleep defects suggests that they may be a systemic readout of primary molecular dysfunction in HD, and cAMP/PKA could be established as prevenient indicators of disease and serve as potential therapeutic targets for intervention $[96,97]$.

\subsection{Protein Targets as a Potential Treatment of HD Using the Drosophila Model}

\subsubsection{Transcriptional Factors}

Other proteins and genes have been explored as possible drug targets, including the transactivation domain (TAD) of a self-regulated transcription factor codified by the $c-M y c$ gene. The tissue-specific upregulation of Drosophila c-Myc (dmyc) dominantly suppresses polyQ-mediated toxicity in an HD Drosophila model (UAS-mRFP.Htt.138Q), mostly by improving histone acetylation and re-establishing the global transcriptional impairment $[98,99]$. In humans, the $c-m y c$ gene is translated into three distinct isoforms that produce three corresponding protein products, namely: c-Myc1, c-Myc2, and c-MycS. C-MycS has an unusual form of regulation, as it acts as a dominant negative suppressor of c-Myc1 and c-Myc2 functions. Recently, it was proposed that, similar to dmyc, the targeted expression of human $c-m y c$ in flies also suppresses polyQ-induced neurodegeneration via an analogous mechanism [99]. Furthermore, the TAD of human c-Myc appeared to be critical for the rescue event. It was determined, using multiple Drosophila transgenic lines that independently expressed three different transcript isoforms encoded by human c-myc, that similar to its Drosophila homologue $(d m y c)$, the targeted expression of human c-myc suppresses polyQ-mediated neurotoxicity, both phenotypically and functionally. Therefore, c-Myc is a promising target for the design of novel drug molecules against HD [99].

Transcriptional dysregulation is one of the mechanisms underlying polyQ diseases and can be partially explained by the fact that HTT binds to several transcription factors. Mutant $h t t$ binds to p300, CREB binding protein, and Pcaf, inhibiting their activities mainly as a result of decreased histone acetylation. The range of histone acetyltransferases (HATs) interacting with mutant $h t t$ and, consequently, the reduction in HAT activity, have been evaluated using Httex1pQ93, a Drosophila transgenic model of HD generated by standard P element-mediated transformation [100]. A decrease in Pcaf (a complex involved in DNA repair) leads to a reduced average of rhabdomeres per ommatidium in the flies' expression a mutant $h t t$ and a Pcaf null allele, compared to the control sibling flies only expressing a mutant $h t t$; indicating that reduced Pcaf levels enhance neurodegeneration [101]. Interestingly, the eclosion of the flies expressing Pcaf and htt simultaneously resulted in a non-significant higher degeneration than the sibling controls expressing the mutant $h t t$. Additionally, the soluble Pcaf protein is altered in Httex1pQ93 flies and the mutant $h t t$ expression is not reduced; taken together, these results indicate that the reduction of Pcaf has a significant impact on HD pathology, however, therapeutic strategies to elevate the Pcaf levels are ineffective in ameliorating HD pathology $[100,101]$. The overexpression of Pcaf, however, probably requires other additional factors, in order to effectively increase the level of soluble Pcaf in Httex1pQ93 [101]. 
Table 1. Drosophila mutants named in Section 7. UAS—upstream activating sequence; UCP—uncoupled protein; HTT—huntingtin; CAG—cytosine-adenine-guanine; HD-Huntington's disease; * Referenced in text as.

\begin{tabular}{|c|c|c|c|}
\hline $\begin{array}{l}\cdot \text { Allele Symbol } \\
\left({ }^{*} \text { Referenced in text as }\right)\end{array}$ & Alternative Names & FlyBase ID & General Description \\
\hline $\begin{array}{l}\cdot \text { Hsap } \backslash \text { HTT200Q.UAS } \\
{ }^{*} \text { FL-HTTQ200 }\end{array}$ & $\begin{array}{l}\text { Hsap } \backslash \text { HTT200Q.Scer } \backslash \text { UAS } \\
\text { Hsap }\end{array}$ & FBal0323497 & $\begin{array}{l}\text { UAS regulatory sequences drive the expression of a full-length } \\
\text { Hsap } \backslash H T T \text {, containing an expanded } 200 \text { polyQ repeat. Induces rapid } \\
\text { age-progressive decline of locomotor abilities in adult flies. } \\
\text { Progressive defects of locomotor behavior. }\end{array}$ \\
\hline $\begin{array}{l}\cdot H s a p \backslash \text { HTTQ128.Scer } \backslash \text { UAS } \\
* p U A S-H t t 128 Q\end{array}$ & 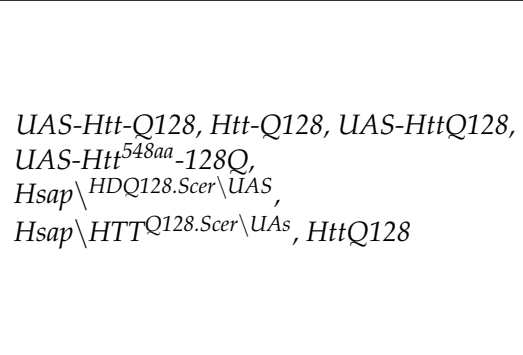 & FBal0156385 & $\begin{array}{l}\text { Scer } \backslash \text { UAS sequences drive expression of the N-terminal } 548 \text { aa of the } \\
\text { Q128 Hsap } \backslash \text { HD cDNA, which encodes the pathogenic protein. } \\
\text { Defective for behavior, circadian rhythm, eye color, locomotor } \\
\text { behavior, and neuroanatomy. Reduced photoreceptor depolarization } \\
\text { and complete abolishment of synaptic transmission in response to } \\
\text { light. Cytoplasmic Hsap } \backslash \text { HD aggregates are seen in neurons and } \\
\text { non-neural tissues, aggregates are transported in larval motor axons, } \\
\text { and accumulate in presynaptic neuromuscular junction terminals. } \\
\text { Uncoordinated movement and abnormal grooming behavior. } \\
\text { Premature death. }\end{array}$ \\
\hline $\begin{array}{l}\cdot \text { Hsap } \backslash H T T{ }^{Q 93 . e x 1 . S c e r ~} \backslash \text { UAS } \\
\text { *Httex1pQ93 } \\
\text { * UASHTT-EX1-PQ93/CyO } \\
\text { *UAS-Htt exon1-Q93 } \\
\text { * Htt93Q }\end{array}$ & $\begin{array}{l}\text { UAS-Httex1p Q93, Httex1p Q93, UAS-htt } \\
\text { exon-1-Q93, UAS-Httex1p-Q93, } \\
\text { P\{UAS-Httex1p Q93\}, Htt93Q, } \\
\text { Httex1-93Q, UASHTT-EX1-PQ93, } \\
\text { HttEx1Q93, P\{UAS-Httex1p Q93\}4F1 }\end{array}$ & FBal0127292 & $\begin{array}{l}\text { Leads to an obvious loss of one or more photoreceptors, leading to a } \\
\text { disorganization of ommatidia, exhibiting a progressive loss of vision. } \\
\text { Results in the formation of aggregates in larval eye imaginal discs } \\
\text { and subsequent age-dependent retinal degeneration and visual } \\
\text { impairment. Neural degeneration and alteration of the diameter of } \\
\text { synaptic vesicles, accumulation of organelles is seen in neurons } \\
\text { producing a defect in axonal transport, increasing cell death. Initially } \\
\text { hyperactive with gradual loss. Reduces mobility and lifespan. }\end{array}$ \\
\hline $\begin{array}{l}\text { HsapHTT Q138.Scer } \backslash \text { UAS.T:Disc } \backslash \text { RFP-mRFP } \\
* \text { UAS-mRFP.Htt.138Q }\end{array}$ & Hsap $\backslash H T T^{\text {Q138.Scer } \backslash U A S . T: D i s c ~} \backslash$ RFP-mRFP & FBal0267405 & $\begin{array}{l}\text { Containing a pathogenic tract of } 138 \text { polyQ repeats. Defects on } \\
\text { grooming behavior, locomotor behavior, neuroanatomy, and } \\
\text { increased cell death in the central brain and optic lobes. Neurons } \\
\text { display morphological indicators of reduced neuronal health, } \\
\text { including smaller neuromeres, increased branching, and reduced } \\
\text { axonal connectivity. Premature death. }\end{array}$ \\
\hline $\begin{array}{l}\cdot \text { UAS-mRFP.Htt.15Q } \\
* \text { UAS-mRFP.Htt.15Q }\end{array}$ & 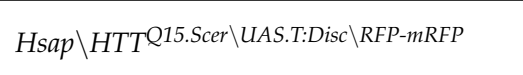 & $\begin{array}{l}\text { Control for } \\
\text { UAS-mRFP.Htt. }{ }^{138 Q}\end{array}$ & Non-expanded human HTT control. \\
\hline
\end{tabular}


Table 1. Cont.

\begin{tabular}{|c|c|c|c|}
\hline $\begin{array}{l}- \text { Allele Symbol } \\
(* \text { Referenced in text as) }\end{array}$ & Alternative Names & FlyBase ID & General Description \\
\hline $\begin{array}{l}\text {. GMR-GAL4UAS-127Q } \\
\text { * GMR-GAL4UAS-127Q }\end{array}$ & $Z z z z \backslash C A G^{127 Q . S c e r ~} \backslash$ UAS.T:Ivir $\backslash H A 1$ & $\begin{array}{l}\text { Information in the } \\
\text { literature [102] }\end{array}$ & Containing the expanded 127-CAG repeat. Severe abnormal eyes. \\
\hline $\begin{array}{l}\text { · Hsap } \backslash H T T \text { GMR.Q120 } \\
\text { * gmr-Htt(exon1)Q120 }\end{array}$ & $\begin{array}{l}\text { gmr-HttQ120 } \\
\text { gmr-Htt-Q120 } \\
\text { gmr-Q120 } \\
\text { Q120 } \\
\text { gmrHtt(exon1)Q120 } \\
\text { GMR-HD.Q120 } \\
\text { GMR-HTT.Q120 } \\
\text { Between others }\end{array}$ & FBtp0010067 & $\begin{array}{l}\text { Expression of Hsap } \backslash \text { HD amino acids 1-170, with } 120 \text { CAG } \\
\text { glutamine repeats is governed by the glass multiple reporter (GMR) } \\
\text { promoter. Results in neurodegeneration and the loss of rhabdomeres. } \\
\text { Show a progressive decrease in the number of visible rhabdomeres } \\
\text { per ommatidium. The eyes of flies expressing this allele } \\
\text { progressively degenerate. }\end{array}$ \\
\hline $\begin{array}{l}\text { Dmel } \backslash \text { Rab5 }{ }^{\text {Scer } \backslash U A S . T: A v i c \backslash G F P-E G F P} \\
* \text { CyO/If; } \\
\text { UAS-Rab5-EGFP-elavGal4/MKRS }\end{array}$ & $\begin{array}{l}\text { UAS-GFP-Rab5 } \\
\text { Rab5-GFP } \\
\text { UAS-Rab5-GFP } \\
\text { GFP-Rab5 } \\
\text { UAS-GFPRab5 } \\
\text { UASrab5-GFP } \\
\text { UAS-GFP:Rab5 }\end{array}$ & FBal0182041 & $\begin{array}{l}\text { Modeled by Hsap } \backslash H T T G M R \text {.Q120. Flies expressing this allele show } \\
\text { trichome polarity defects in the wings, and alterations in the } \\
\text { synaptic area under the regulation of Scer } \backslash \text { GAL4 does not } \\
\text { significantly alter the synaptic area. }\end{array}$ \\
\hline $\begin{array}{l}\cdot \text { Dmel } \backslash H s f^{f l s N A . S c e r} \backslash U A S \\
* \\
\text { *UAS-HSF1-RNAi }\end{array}$ & $\begin{array}{l}\text { HSF1 RNAi } \\
\text { UAS-HSf.RNAi } \\
\text { UAS-HSF1-RNAi } \\
\text { HsflsRNA.Scer } \backslash \text { UAS }\end{array}$ & FBal0283110 & Defects on neuroanatomy. Shows degeneration including in the eyes. \\
\hline $\begin{array}{l}\text { - Dmel } \backslash \text { Glut1 }{ }^{\text {Scer } \backslash \text { UAS.cBa }} \\
\text { *DmGluT1 }\end{array}$ & $\begin{array}{l}\text { DmGluT1 } \\
\text { Glut1 } 1_{\text {Scer } \backslash U A S . c B a}\end{array}$ & FBal0256734 & $\begin{array}{l}\text { Defects for locomotor behavior, climbing ability, and } \\
\text { reduced lifespan. }\end{array}$ \\
\hline $\begin{array}{l}\text { - Dmel } \backslash B m c p^{S c e r} \backslash U A S . c B a \\
\text { *DmUCP5 }\end{array}$ & $\begin{array}{l}\text { DmUCP5 } \\
\text { Bmcpscer } \backslash U A S . c B a\end{array}$ & FBal0256733 & $\begin{array}{l}\text { Defects for locomotor behavior, bang sensitive. Shows glial } \\
\text { pathology, neuronal defects. Reduction in life expectancy. }\end{array}$ \\
\hline For detailed information of driver & tp://flybase.org/search/disea & & \\
\hline
\end{tabular}




\subsubsection{Autophagy and Cargo Recognition}

The main function of the vertebrate HTT protein in the cell has not been fully elucidated. As previously mentioned, reports suggest that HTT has a dual function as a scaffold in selective autophagy, by promoting cargo recognition and autophagy initiation [103]. Physiologically, autophagy is regulated in the healthy cell; it is a destructive mechanism that disassembles unnecessary or dysfunctional constituents during cell processes [104]. Defective autophagy in HD-affected neurons is exhibited by the presence of empty autophagosomes and promotes cargo protein failure. To understand this process, one study used homozygous Drosophila mutants lacking the htt gene (dhtt-ko) and tested the physiological function of $h t t$, tracking the ectopic expression of a truncated form of the microtubule-binding protein Tau (Tau- $\Delta$ C) [103]. This resulted in a prominent collapse of the thorax in $d h t t-k o$ flies as a result of severe muscle loss, and an accelerated decline in mobility and lifespan, which was not observed by the Tau expression alone. These phenotypes were fully rescued by the dhtt genomic rescue transgene. Furthermore, the expression of human HTT in dhtt-ko flies rescued both the mobility and longevity defects of $d h t t-k o$ mutants and partially rescued the Tau-induced morphological and behavioral defects of $d h t t-k o$ flies, suppressing most of the autophagic defects observed in dhtt-ko [103].

\subsubsection{The Aggregation Mechanism}

There is evidence that the htt protein aggregates can spread between neurons [105]. Although there is information on how proteins pass from one cell to another in this disseminating protein mechanism, the specific processes remain unclear. There is some evidence indicating that this occurs through synaptic connections, tunneling nanotubes, or by means of exosome machinery using the UAS-mRFP.Htt.138Q HD fly model with the Or83b-Gal4 driver to target the expression into the axonal terminals of the antennal lobe, where the htt protein aggregates are located at the synaptic terminals in the antennal lobe of the Drosophila central brain when expressed in olfactory receptor neurons. These aggregates start to spread to other brain regions. In order to test if this phenomenon is unique to the toxic polyQ form, a construct with a much shorter polyQ tract was used as a control, UAS-mRFP.Htt.15Q, which does not form aggregates and therefore does not spread through the brain [106]. The underlying mechanism by which htt extends throughout the brain involves SNARE (SNAP [Soluble NSF \{N-ethylmaleimide-sensitive factor\} Attachment Protein] REceptor) machinery; this was shown by knock down $N$-ethylmaleimide-sensitive fusion protein 1 (NSF1) using the UAS-comt ${ }^{R N A i}$ method, as NSF1 is required for SNARE disassembly and for complex recycling, as well as for lysosomal trafficking and autophagy. This strategy showed a significant decrease in htt spreading. Similar results were observed when interfering with the dynamin function, confirming that htt aggregate release requires dynamin and NSF1 activity through a SNARE mechanism and its insertion into other neurons by active endocytosis [107].

\subsubsection{The Fly's Eye as a Tool for the Study of HD}

Considering the previous data, suppressing the toxicity generated by the polyQ mutation in htt should be a fundamental target. A pioneer study using the Drosophila HD model and other polyQ diseases (GMR-GAL4UAS-127Q) was performed using transposable elements affecting the fly's eye, in order to screen for genetic factors modifying the degeneration caused by the polyQ expression [102]. Among the 7000 P-element insertions, several suppressor strains were isolated, two of which led to the discovery of the suppressor genes. The first strain is the predicted $d H D J 1$ product, which is homologous to the human HEAT shock protein 40lHDJl. The second strain, dTPR2, is homologous to the human tetratricopeptide repeat protein 2. Each of these proteins contains a chaperone-related J domain. The suppression of the polyQ toxicity was verified in transgenic flies, which had severe externally evident eye aberrations, and were used to screen for dominant modifiers of the polyQ repeat toxicity by examining the genes in the vicinity of a series of P-element chromosomal 
insertion sites. The abnormal eyes of the transgenic flies dramatically improved in the presence of the suppressor P-element insertion. With this insertion, the eye preserved its globular structure, pigmentation, and a uniform bristle arrangement [102]. Reports like this create higher hopes for the development an effective treatment to stop HD progression. Another encouraging study describes the potential of curcumin ([1E,6E]-1,7-bis [4-hydroxy-3-methoxyphenyl]-1,6-heptadiene-3,5-dione), a polyphenolic compound with an outstanding safety profile. Curcumin is the major bioactive component of turmeric, a phytochemical and an ingredient commonly used in Asian cuisine and medicine. Recent studies have discovered that curcumin is a positive therapeutic compound, given its strong antioxidant, anti-inflammatory, and anti-protein aggregation effects [108]. Curcumin suppresses degeneration of photoreceptor neurons (indicative of disrupted internal eye architecture) in transgenic Drosophila expressing the exon1 fragment of mutant $h t t$ with 48 or 93 glutamine residues (httex1pQ93 and Q48 peptides) [109,110]. Curcumin also ameliorates the extensive degeneration and external dysmorphology of the eye, caused by the expression of Httex1pQ93 in all of the cells of the Drosophila's eye [110]. This progressive loss of photoreceptor cells expressing httex1pQ93 and Q48 peptides can be observed quantitatively (as a measure of neurodegeneration) with the pseudopupil technique [111]. Nurturing the fly httex1pQ93 and Q48 with curcumin-supplemented food was enough to suppress the photoreceptor neuron degeneration in a dose-dependent manner. The most significant suppression was achieved at a fed dose of $10 \mu \mathrm{M}$, showing that dietary curcumin suppresses polyQ-induced neurodegeneration and internal morphological defects of the eye, with no side effects. Reports also found a substantial reduction in polyQ-induced cell death in third-instar eye discs, due to the administration of curcumin, which has been implicated in alleviating cytotoxicity, oxidative stress, and apoptotic cell death in neurological disorders [110]. A fact to thoroughly consider is that the prevalence of neurodegenerative diseases among people living in the Asian subcontinent, where spices are regularly consumed, is lower than in Western countries (see [38]). Dietary habits could be a critical factor for producing significant improvements in HD prevention and treatment [110].

\subsubsection{Metabolic Imbalance}

HD induces imbalances in several metabolites in humans and in non-fly HD models; mutant huntingtin interacts directly with metabolites such as valine, alanine, glutamine, and glycerol [112]. By means of nuclear magnetic resonance spectroscopy in a Drosophila HD model (UASHTT-EX1-PQ93/CyO), alterations in metabolomics were detected in several phenotypes expressing htt with different numbers of polyQ repeats, showing mainly perturbations in the development of classified adult ommatidia; these transgenic lines carried 20 (control), 93 (intermediate), and 127 (diseased) polyQ repeats. The main result of the metabolomic profile in the HD flies was that the major metabolite imbalance included nicotinamide adenine dinucleotide (NAD), lactate, and pyruvate, compared to the control profile (20 polyQ). Interestingly, these metabolites are related to the metabolic pathways involved in cellular energetics. In particular, decreased NAD levels could be associated with cell death (a hallmark of HD) as a result of a deficit in cellular energy supply. Additionally, an increase in the lactate/pyruvate ratio compared to the control suggested mitochondrial dysfunction. This observation is similar to the increased pyruvate/lactate ratio found in HD patients. Based on the above information, the imbalance in the NAD and lactate/pyruvate ratios are obvious perturbations in cellular energetics of HD fly tissues [113].

\subsubsection{Transport Proteins and Trafficking}

Rab GTPases constitute the largest family of small GTPases; they are highly active in neurons and are key regulators at intracellular membrane trafficking. Different Rab GTPases are involved in early transport vesicle formation through membrane-vesicle interaction and are located in the ER-Golgi, early endosomes, late endosomes, and synaptic vesicles [6,114]. Drosophila native htt seems to participate in axonal transport, in the movement of several Rab proteins, and in the trafficking of Rab-containing vesicles, thus impairing the anterograde and retrograde motility when htt is expressed 
in reduced amounts, and stimulating the anterograde motility of Rab2-a GTPase linked to its corresponding mammalian Rab [80]. At least 60 different Rab GTPase family members are present in the human genome; meanwhile, in Drosophila there are only 26 members. The Rab5 GTPases are regulators of intracellular membrane trafficking in early endocytosis and they also play a role in autophagy [115]. In HD, Rab5 GTPases mediate the degradation of the mutant htt protein, which contains an abnormally long polyQ tract. Interestingly, in mammalian cells (COS-7 and MEF cells), Rab5 activity can decrease the polyQ toxicity and its aggregation. Furthermore, Rab5 overexpression can rescue the typical rhabdomere degeneration in photoreceptors in the Drosophila HD model (CyO/If; UAS-Rab5-EGFP-elavGal4/MKRS). Additionally, protein interactions showed that Rab5 is a member of a complex that includes the proteins, Beclin 1 and PI 3-Kinase Vps34, which regulate the early steps of autophagosome formation. The 3MA treatment (a PI-Kinase inhibitor) and siRNA knockdown of Vps34 had similar effects on the Rab 5 loss of function; the autophagosomal precursors accumulated, whereas autophagic vacuoles decreased. This accumulation of precursor structures was observed in response to Rab5 inhibition. Otherwise, Vps34 might block the progression from early autophagosomal structures to mature autophagic vacuoles [116].

Morphological studies in one of the first HD mouse models, the R6/2, with 116 to 150 CAG repeats, manifested a behavioral phenotype very similar to human HD [56], indicating a clear decrease in the density of MSSN the excitatory synaptic contacts, in addition to a significant reduction of the postsynaptic spine terminal [117]. In a Drosophila HD model, the accumulation of pathogenic huntingtin protein (UAS-mRFP.Htt.138Q) in motor-neuron terminals changed the synaptic morphology, thus altering axonal branching and leading to neuromuscular junction overgrowth in a dose-dependent manner. Furthermore, this excessive growth of synaptic connections induces pupal lethality in most cases. The synaptic overgrowth phenotype is related to abnormal endocytosis and endosomal traffic in the $\mathrm{HttQ138}$ model. This mutant huntingtin exhibits protein-protein interaction with Sorting Nexin 16 (Snx16), a transport protein with a critical role in intracellular protein trafficking from early to late endosomes. It also regulates the trafficking of bone morphogenetic protein (BMP) receptors, which belong to the transforming growth factor-beta (TGF-beta) superfamily. HttQ138-Snx16 interaction in early endosomes disrupts normal endosomal trafficking and increases the size and number of endosomes that upregulate the BMP signaling in the nerve terminals of flies, thus triggering a robust overgrowth not only at the axon level, but also of the smaller synaptic bottoms or axonal branches [118].

\subsubsection{Heat Shock Proteins}

One of the most common pathological features of HD is protein misfolding and the accumulation of mutant proteins as insoluble aggregates. The HEAT shock response (HSR) is a highly conserved mechanism in order to maintain cellular integrity. HSR transcribes multiple chaperones, including heat shock proteins (HSPs), where HSF1 is the principal transcription regulator of HSR components, and HSP90, which is known for repressing HSF by itself or associated with a multichaperone complex [119]. To determine whether the HSR mechanism had been lost in both the murine and fly models of HD, the transcription, expression, and phosphorylation of HSF1 were analyzed. The HSF1 levels decreased in HD and clearly increased upon chronic dexamethasone treatment, a synthetic glucocorticoid, in different brain regions of the HD models and, interestingly, in the control animals. These findings suggest that the dexamethasone induced HSF1 transactivation in HD as well as in wild-type animals. Dexamethasone reduces motor symptoms and protein aggregates in the neostriatum, cerebellum, and cortex in an HD murine model [120] and in Drosophila eye imaginal discs of larvae in an HD fly model (UAS-HSF1-RNAi) [121]. The effect of dexamethasone in the HSF1 induction was confirmed with an HSF1 RNAi. The mechanism by which the dexamethasone treatment induces HSF1 upregulation was associated with the down-expression of HSP90 in HD 150Q cells, HD mice, and in a fly model; suggesting anti-inflammatory drugs, such as dexamethasone, as a potential pharmacological treatment of HD and other polyQ disorders [121]. 


\subsection{8. mTOR Pathway Inhibition}

In cell lines, inhibitors of the autophagy-lysosome pathway impair the alterations in the mutant $\mathrm{htt}$ fragment turnover. Previously, autophagy induction was effective at protecting against the toxic effects of mutant htt by means of pharmacological treatment with rapamycin, a specific inhibitor of $m T O R$, which in turn inhibits autophagy activity [122]. Rapamycin reduces protein aggregate formation and cell death only in the early hours of post-transfection, suggesting that inducing early rapamycin autophagy in vivo may attenuate HD effects against the toxicity of htt accumulation. Remarkably, mTOR is sequestered into htt aggregates; this interaction was confirmed by chimeric proteins, tissue immunolabeling, and Western blotting, as well as by a co-immunoprecipitation assay, suggesting that this strong interaction could alter the nucleocytoplasmic transport that is crucial for mTOR activity. To corroborate this, the mTOR activity was inferred by phosphorylating 4E-BP1 and S6K1, two downstream proteins of the mTOR pathway. Phosphorylation was reduced in mutant cells with aggregates, and no variations were observed when adding rapamycin. However, rapamycin inhibited the S6 activity in the control cells, and decreased the rhabdomere neurodegeneration was observed in the fly model ( $g m r-H t t[$ exon1]Q120). This implies that mutant $h t t$ causes translational deregulation by altering the mTOR signaling pathway. The results suggest that only early treatment with rapamycin can attenuate the HD characteristics, by inducing autophagy mediated by mTOR inhibition [123].

\subsubsection{Oxidative Stress Associated to HD}

As previously mentioned, htt is a ubiquitous protein spread throughout the body during all stages of life. Interestingly, HD patients exhibit an important prevalence of cardiac failure as a concomitant pathology. Using a Drosophila model (Httex1pQ93) of cardiac amyloidosis that exhibited accumulation of htt protein with different polyQ repeat lengths (PolyQ-25; PolyQ-46; PolyQ-72; PolyQ-102), it was determined that longer polyQ repeats (PolyQ-72 and PolyQ-102) in fly hearts were a molecular factor for cardiac dilation and reduced heart contractility [107]. Moreover, fly hearts with longer polyQ exhibited reduced myofibrillar content and severe myofibrillar disorganization; and subsequently, the accumulation of toxic aggregates and severe mitochondrial fragmentation that induced an increase in oxidative stress in PolyQ-72 and PolyQ-102, as demonstrated with the superoxide indicator dihydroethidium. To verify the role of oxidative stress, the superoxide dismutase (SOD1) enzyme was overexpressed and treated with the antioxidant agent, Resveratrol, which partially suppressed the cardiac dysfunction induced by the polyQ repeats. Likewise, the overexpression of UNC-45, a chaperone necessary for myosin folding and accumulation, also improved heart contraction and heart rate regularity, suggesting that polyQ protein misfolding plays a role in mitochondrial dysfunctions and subsequent oxidative stress, inducing cardiac disease [124]. Finally, metal-induced oxidative stress, in particular copper-dependent toxicity, was shown to be an important component of disease progression in a Drosophila model of HD [125].

Oxidative stress is an outstanding feature to consider in HD. When screening a yeast open reading frame collection, antioxidants that suppressed $h t t 103 Q$ toxicity were identified. The antioxidant genes of glutathione peroxidase GPx1 and GP $x 2$ are overexpressed in a cell model of mutant $h t t$, suppressing $h t t 103 Q$ toxicity and decreasing caspase (a protease enzyme family with an essential role in inflammation and programmed cell death) activity; whereas $m G P x 1$ provides neuroprotection in the eyes of HD flies and restores decreased locomotor activity and circadian arrhythmia in a Drosophila HD model. Similar observations in decreasing the htt toxicity were reported when using Ebselen, a mimic molecule of glutathione peroxidase, widely used in clinical practice against strokes. It is known that oxidation contributes to the chronic development of this pathology; however, the overexpression of other antioxidants, such as superoxide dismutase, catalase, and glutathione reductase, do not protect against $h t t 103 Q$-mediated toxicity [126]. 


\subsubsection{The Kynurenine Pathway}

The kynurenine pathway metabolite kynurenic acid (KYNA) is a modulator of cholinergic and glutamatergic neurotransmission. KYNA production is dependent on kynurenine 3-monooxygenase (KMO) [127]. Several neurodegenerative disorders are related to alterations in the kynurenine pathway (KP) of tryptophan degradation. KP contains metabolites shown to be neuroactive, namely: KYNA (neuroprotective) and 3-hydroxykynurenine (3-HK) (neurotoxic). In htt93Q, a fly model of HD, the 3-HK/KYNA ratio increases, supporting a pathogenic role for KP. To explore the effects of KP manipulation in this HD fly model, the branching point between the 3-HK and KYNA synthesis was modulated by KMO. The genetic interruption of KMO with a mutant (cn3) showed a $26 \%$ rescue in the photoreceptor neurons on the first day (rhabdomeres) and a $47 \%$ rescue on the seventh day; whereas with RNAi, the genetic interruption of KMO showed a $65 \%$ and $67 \%$ rescue. Additionally, in both cases, the 3-HK and 3-HK/KYNA ratio decreased. Regarding a potential pharmacological modulator, UPF 648, a KMO inhibitor, was tested in $H t t 93 Q ; 90 \%$ of the flies fed with this inhibitor rescued and increased KYNA, and the 3-HK/KYNA ratio subsequently decreased, supporting the idea that the KMO inhibitor drugs reduce the neurodegenerative effects of HD. Finally, when the $H t t 93 Q \mathrm{cn} 3$ flies were fed with 3-HK, a neurodegenerative process was restored, and when the flies were fed with KYNA, a protective effect was observed, supporting the neuromodulator effect of 3-HK and KYNA. These findings led to the conclusion that the metabolites of the KP pathway modulate neurodegeneration and thus have the potential to be used as a pharmacological therapy [127]. It should be noted that the commonly used white Drosophila mutant is defective in 3HK accumulation. An issue to be considered when studying the current Drosophila models of HD is that the white mutant has been used as a convenient marker for transgenesis [43].

\subsection{The Glia; Studying an Almost Unknown Factor Involved in HD Pathogenesis Using the Drosophila Model}

Despite efforts to define the role of glial cells in HD pathogenesis [128-130], or the effects that abnormal polyQ repeats have on glia [131], these aspects remain almost unattended in HD. Glial cells express huntingtin constitutively; the aggregation of mutant htt in glia induces locomotor deficits and decreases lifespan in the fly HD model $[132,133]$. This model (DmGluT1), with locomotor deficits and early lethality, could be rescued by the overexpression of DmUCP5, a homologue of mitochondrial uncoupled protein 5 (UCP5) in humans; generating, for this reason, a Drosophila DmUCP5 transgenic line [134]. Protein aggregation in glial cells can cause dysfunction in both neurons and glia, as it is intrinsically cytotoxic and negatively influences the nearby neurons. The activation of glial phagocytosis is one way by which the aggregates or damaged neurons are cleared from the CNS [135]. The UAS-GAL4 system is a powerful tool that has been used in Drosophila as a selective strategy to express mutant htt in glial cells so as to identify the htt implications [132]. In a recent report, the Drosophila model system was established to assess the role of phagocytic glia in the uptake and clearance of polyQ aggregates formed by a pathogenic fragment of htt in neurons within an intact CNS. The report determined that the mutant htt aggregates localized in neurons could be eliminated by glia through a phagocytic process that requires the cell surface engulfment receptor, Draper [136]. Phagocytosed neuronal htt aggregates can access and initiate a prion-like assimilation of normally soluble, wild-type htt proteins in the glial cell cytoplasm. These findings suggest that the phagocytic clearance of neuronal htt protein aggregates by glia might contribute to the spreading of pathogenic protein aggregates in neurodegenerative disease. Moreover, these findings have important implications for the potential role of glia as a fundamental mediator of protein aggregation in the suppression and/or progression of neurodegenerative diseases [136]. Abnormal PolyQ expansion in the blood-brain barrier and blood-retina barrier glia impaired both barriers and reversed the polarity in electroretinography. Moreover, polyQ repeats also restrict fly lifespan and reduce the transcriptional levels of Repo, a transcriptional factor necessary for glia differentiation. Otherwise, the expression of chaperones HSP40 and HSP70, a bi-complex protein that regulates adenosine triphosphate, partially rescued the shortened lifespan caused by htt-expanded proteins, suggesting that polyQ aggregates may 
affect the normal expression of transcriptional factors like Repo, which is rescued by HSP chaperones, therefore inhibiting htt protein aggregate formation [131].

\section{Concluding Remarks}

In conclusion, a summary of the HD changes and the consequences of protein aggregation mentioned throughout the text using HD fly models are depicted in Figure 3.

1. A double proteolysis of both the N-terminal and C-terminal becomes highly detrimental for the dynamin 1 protein, leading to reticulum stress and malfunction.

2-3. The increase of cAMP and CAMP/CREB produce early onset sleep defects, inducing an increase in PKA signaling. Decreased cAMP/CREB activity could partially attenuate sleep alterations. Both cAMP and PKA levels could be established as indicators of disease and/or therapeutic targets.

4. Homo sapiens and Drosophila melanogaster c-Myc suppress polyQ toxicity by improving histone acetylation. Re-establishing the transcriptional impairment of c-Myc could be a novel pharmacological target for HD.

5. Mutant htt binds to Pcaf (a complex involved in DNA repair), inducing a decrease in the histone acetylation and Pcaf levels, and worsening the neurodegenerative process.

6. Defective autophagic activity was exhibited by the presence of empty autophagosomes, promoting failure of the cargo proteins.

7. Dissemination of htt protein occurs because of synaptic connections, tunneling nanotubes, or by means of exosome machinery. Release of mutant $h t t$ requires dynamin and NSF1 activity through NSF attachment to protein receptor SNARE, and its recapture into other neurons occurs by active endocytosis.

8. Using P-element insertions, two suppressor genes were discovered (dHDJ1 and dTPR2, with their respective Homo sapiens homologous). Both insertions dramatically decreased the aberrations caused by polyQ toxicity.

9. Curcumin-supplemented food and copper chelation ameliorate polyQ degeneration and cell death.

10. Major metabolite imbalances include lowered NAD (linked with cell death due to a deficit in cell energy) and an increased lactate/pyruvate ratio, suggesting mitochondrial dysfunction.

11. Native htt in Drosophila seems to participate in axonal transport, Rab protein movement, and trafficking of Rab-containing vesicles. Additionally, in the presence of mutant htt Rab5 (a regulator of intracellular membrane trafficking), a protein with a key role in autophagy activity, which decreases as a consequence of polyQ toxicity and aggregation. Overexpression of Rab5 rescues cells from degeneration.

12. Pathogenic htt accumulation in neuron terminals changes synaptic morphology by altering axonal branching, thus leading to neuromuscular junction overgrowth. The htt-Snx16 interaction disrupts normal endosome trafficking and has a general increase in the endosomal size and number.

13. Expression levels of HSP90 and HSF1, a transcription regulator of HSR components, decrease in HD. However, these levels increase upon chronic dexamethasone treatment, which improves motor symptoms and reduces protein aggregates.

14. Autophagy induction was effective at protecting against toxic effects of mutant $h t t$ by applying pharmacological treatment with rapamycin, a specific inhibitor of $m T O R$, which in turn inhibits autophagic activity.

15. Overexpression of the antioxidant glutathione peroxidase GPX1 gene during HD helps to suppress htt toxicity, as well as to decrease specific caspase activity providing neuroprotection and restoring decreased locomotor activity and circadian arrhythmia.

16. The kynurenic pathway (KP), is a modulator of cholinergic and glutamatergic neurotransmission. Several neurodegenerative disorders have been associated with alterations in KP. Dysregulation of KP produces toxic metabolites that can damage several neurons. Flies fed with UPF 
648 , a KM regulator, rescue $90 \%$ of the neurons from damage. UPF 648 has the potential to be used as a pharmacological therapy.

17. The phagocytosed neuronal htt aggregates can access and initiate prion-like assimilation in the glial cell cytoplasm, which might contribute to spreading pathogenic protein aggregates.

18. Mutant htt aggregates expressed in neurons could be eliminated by glia through a phagocytic process that requires the cell surface engulfment receptor, Draper.

19. Abnormal polyQ repeats also restrict fly lifespan and reduce transcriptional levels of Repo, a transcriptional factor necessary for glia differentiation.

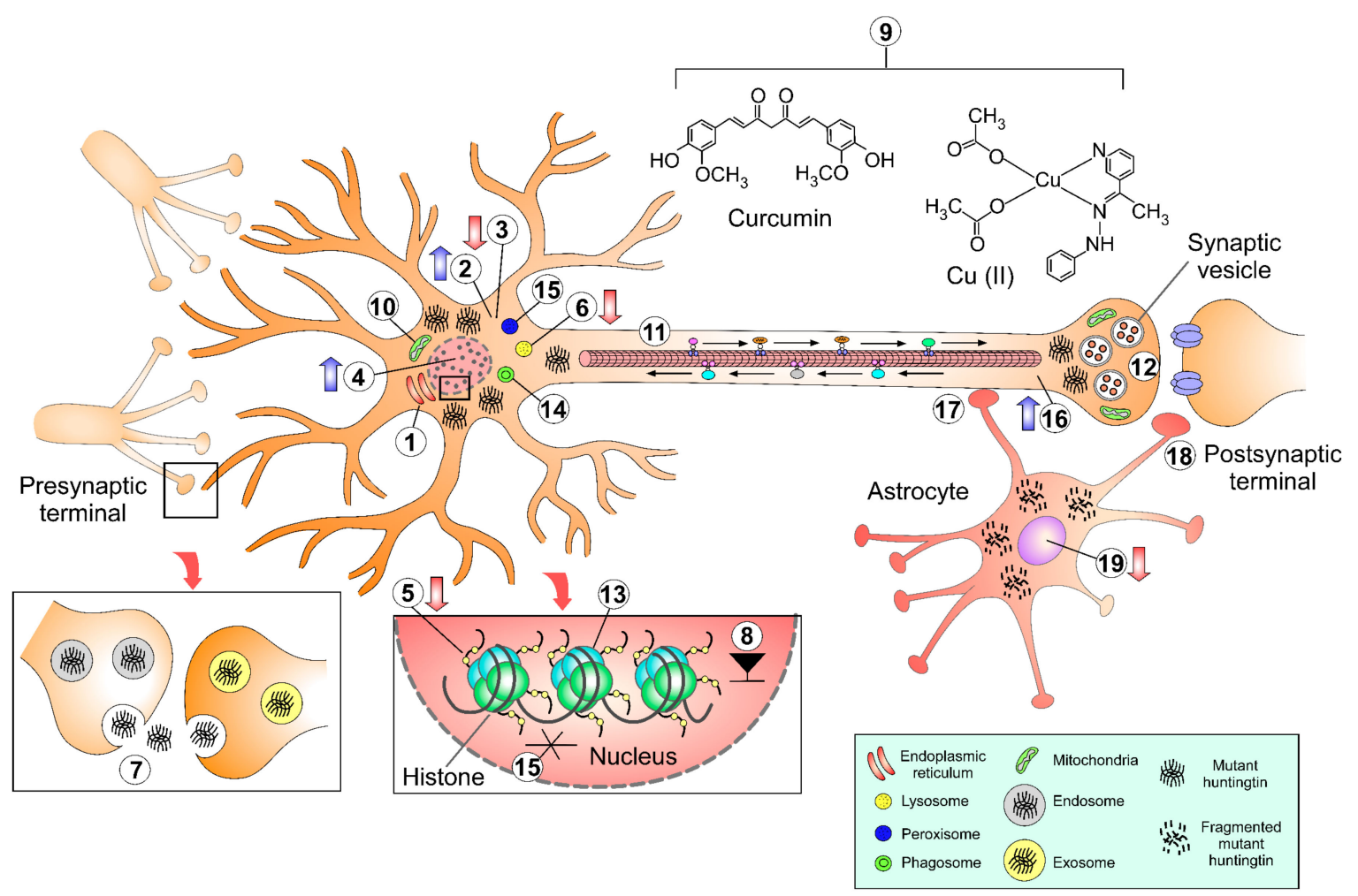

Figure 3. Some examples of the legacy of the fruit fly in solving molecular questions in Huntington's disease. Numbers are related to the conclusions of this review. Upwards arrows (blue) indicate increasing expression. Downwards arrows (red) indicate decrease in expression.

\section{Insights and Directions for Future Research}

The Drosophila model has been used over many years to study several of the consequences induced by polyQ disorders linked to HD, because of the simple fact that Drosophila huntingtin does not express an expanded polyQ sequence in its amino terminal domain. However, the following imperative question remains: What have we learned about the disease, taking advantage of the uniqueness of the fruit fly compared with other animal models, and how can we use this knowledge to enrich future research in order to treat this disease more effectively. In order to answer to this question, we propose to increase the research focused on the integrative process using transgenic flies expressing defective interacting proteins, and the mutant polyQ human htt, followed by the validation of behavioral experiments. These model flies can be treated with new molecules, with the aim of developing more effective and selective drugs than the ones that are currently being used. These molecules can be addressed to one or more of the multiple targets potentially involved in the development of the disease. Among these targets are the following: partially stopping the double proteolysis of both htt in the N-terminal and C-terminal; downregulating the cAMP and PKA levels in specific pathways; upregulating $c-M y c$ levels by alternative methods; downregulating or stopping the binding of htt to 
Pcaf, avoiding decreased histone acetylation; targeting and destroying empty autophagosomes and their damaged cargo proteins; downregulating or stopping the interaction of htt with dynamin, NSF1, or the protein receptor SNARE by endocytosis; downregulating or stopping the $h t t-S n x 16$ interaction, which disrupts normal endosome trafficking; downregulating or suppressing the expression of the antioxidant glutathione peroxidase GPx1 gene; and upregulating the levels of Repo, a transcriptional factor necessary for glia differentiation, which is reduced during HD. Also, there are very promising perspectives for performing more extensive research in subjects such as the discovery of genes $d H D J 1$

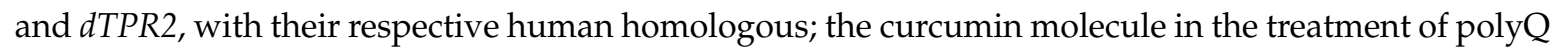
degeneration; the major metabolite imbalance as a consequence of HD; the overexpression of Rab5 (a regulator of intracellular membrane trafficking), and its role in rescuing cell degeneration; some treatments based on dexamethasone, rapamycin, and some inhibitors of the kynurenic pathway, which have been very promising for improving motor symptoms, reducing protein aggregates, and inhibiting autophagic activity. Lastly, a better understanding of some related cellular mechanisms could produce key solutions for HD, for example, understanding prion-like assimilation and the phagocytic process of glia. All of these perspectives offer great possibilities for future lines of research in order to better understand and treat HD, and which would not be possible without the use of the Drosophila model and its extraordinary potential when using tools for gene expression, such as the GAL4/UAS system, UAS-RNAi, P-elements, genetics mosaics, and CRISPR.

Supplementary Materials: Supplementary materials can be found at http:/ /www.mdpi.com/1422-0067/19/8/ 2398/s1.

Author Contributions: A.R.-A. structured the text and content. A.R.-A., A.E.-M., R.P., C.A.M., and M.A.C., reviewed the literature and provided intellectual contributions. A.E.-M., R.P., and A.R.-A. generated the figures. A.R.-A., A.E.-M., R.P., and M.A.C., edited the final version of the review. All of the authors approved the final version of the manuscript. R.P., In memoriam of Yolanda Inés Aránguiz Morales.

Funding: FONDECYT 1151206; RING-CONICYT grant ACT1401 (Maite A. Castro).

Acknowledgments: R.P.: is a postdoctoral fellow of the Chilean CONICYT-FONDECYT program \#3170249. Thanks to Fanis Missirlis, Cinvestav, Mexico, and Ataúlfo Martínez Torres, INB-UNAM, Mexico for the critical revision of the manuscript and intellectual suggestions. Thanks to Jessica G. Norris INB-UNAM, Mexico, and Laura Mendez-Corzo for editing and proofreading the manuscript.

Conflicts of Interest: The authors have no conflict of interest to declare.

\section{References}

1. Heemels, M.T. Neurodegenerative diseases. Nature 2016, 539, 179. [CrossRef] [PubMed]

2. Berrío-Valencia, M.I. Aging population: A challenge for public health. Rev. Colomb. Anestesiol. 2012, 40, 192-194. [CrossRef]

3. The Huntington's Disease Collaborative Research Group. A novel gene containing a trinucleotide repeat that is expanded and unstable on Huntington's disease chromosomes. Cell 1993, 72, 971-983. [CrossRef]

4. Pfister, E.L.; DiNardo, N.; Mondo, E.; Borel, F.; Conroy, F.; Fraser, C.; Gernoux, G.; Han, X.; Hu, D.; Johnson, E.; et al. Artificial miRNAs Reduce Human Mutant Huntingtin Throughout the Striatum in a Transgenic Sheep Model of Huntington's Disease. Hum. Gene Ther. 2018, 29, 663-673. [CrossRef] [PubMed]

5. Snyder, B.R.; Chan, A.W.S. Progress in developing transgenic monkey model for Huntington's disease. J. Neural Transm. 2018, 125, 401-417. [CrossRef] [PubMed]

6. Chan, C.C.; Scoggin, S.; Wang, D.; Cherry, S.; Dembo, T.; Greenberg, B.; Jin, E.J.; Kuey, C.; Lopez, A.; Mehta, S.Q.; et al. Systematic discovery of Rab GTPases with synaptic functions in Drosophila. Curr. Biol. 2011, 21, 1704-1715. [CrossRef] [PubMed]

7. Yan, S.; Tu, Z.; Liu, Z.; Fan, N.; Yang, H.; Yang, S.; Yang, W.; Zhao, Y.; Ouyang, Z.; Lai, C.; et al. A Huntingtin Knockin Pig Model Recapitulates Features of Selective Neurodegeneration in Huntington's Disease. Cell 2018, 173, 989-1002. [CrossRef] [PubMed]

8. Stricker-Shaver, J.N.A.; Yu-Taeger, L.; Nguyen, H.P. Genetic Rodent Models of Huntington Disease; Springer: Cham, Switzerland, 2018; Volume 1049. 
9. Lewis, E.A.; Smith, G.A. Using Drosophila models of Huntington's disease as a translatable tool. J. Neurosci. Methods 2016, 265, 89-98. [CrossRef] [PubMed]

10. Veldman, M.B.; Rios-Galdamez, Y.; Lu, X.H.; Gu, X.; Qin, W.; Li, S.; Yang, X.W.; Lin, S. The N17 domain mitigates nuclear toxicity in a novel zebrafish Huntington's disease model. Mol. Neurodegener. 2015, 10, 67. [CrossRef] [PubMed]

11. Acuna, A.I.; Esparza, M.; Kramm, C.; Beltran, F.A.; Parra, A.V.; Cepeda, C.; Toro, C.A.; Vidal, R.L.; Hetz, C.; Concha, I.I.; et al. A failure in energy metabolism and antioxidant uptake precede symptoms of Huntington's disease in mice. Nat. Commun. 2013, 4, 2917. [CrossRef] [PubMed]

12. Covarrubias-Pinto, A.; Moll, P.; Solis-Maldonado, M.; Acuna, A.I.; Riveros, A.; Miro, M.P.; Papic, E.; Beltran, F.A.; Cepeda, C.; Concha, I.I.; et al. Beyond the redox imbalance: Oxidative stress contributes to an impaired GLUT3 modulation in Huntington's disease. Free Radic. Biol. Med. 2015, 89, 1085-1096. [CrossRef] [PubMed]

13. Solis-Maldonado, M.; Miro, M.P.; Acuna, A.I.; Covarrubias-Pinto, A.; Loaiza, A.; Mayorga, G.; Beltran, F.A.; Cepeda, C.; Levine, M.S.; Concha, I.I.; et al. Altered lactate metabolism in Huntington's disease is dependent on GLUT3 expression. CNS Neurosci. Ther. 2018, 24, 343-352. [CrossRef] [PubMed]

14. Saxena, S.; Caroni, P. Selective neuronal vulnerability in neurodegenerative diseases: From stressor thresholds to degeneration. Neuron 2011, 71, 35-48. [CrossRef] [PubMed]

15. Roselli, F.; Caroni, P. From intrinsic firing properties to selective neuronal vulnerability in neurodegenerative diseases. Neuron 2015, 85, 901-910. [CrossRef] [PubMed]

16. Irvine, G.B.; El-Agnaf, O.M.; Shankar, G.M.; Walsh, D.M. Protein aggregation in the brain: The molecular basis for Alzheimer's and Parkinson's diseases. Mol. Med. 2008, 14, 451-464. [CrossRef] [PubMed]

17. Medeiros, A.T.; Bubacco, L.; Morgan, J.R. Impacts of increased alpha-synuclein on clathrin-mediated endocytosis at synapses: Implications for neurodegenerative diseases. Neural Regen. Res. 2018, 13, 647-648. [PubMed]

18. Cattaneo, E.; Rigamonti, D.; Goffredo, D.; Zuccato, C.; Squitieri, F.; Sipione, S. Loss of normal huntingtin function: New developments in Huntington's disease research. Trends Neurosci. 2001, 24, 182-188. [CrossRef]

19. Cepeda, C.; Tong, X.P. Huntington's disease: From basic science to therapeutics. CNS Neurosci. Ther. 2018, 24, 247-249. [CrossRef] [PubMed]

20. Guo, Q.; Bin, H.; Cheng, J.; Seefelder, M.; Engler, T.; Pfeifer, G.; Oeckl, P.; Otto, M.; Moser, F.; Maurer, M.; et al. The cryo-electron microscopy structure of huntingtin. Nature 2018, 555, 117-120. [CrossRef] [PubMed]

21. Schulte, J.; Littleton, J.T. The biological function of the Huntingtin protein and its relevance to Huntington's Disease pathology. Curr. Trends Neurol. 2011, 5, 65-78. [PubMed]

22. Caviston, J.P.; Holzbaur, E.L. Huntingtin as an essential integrator of intracellular vesicular trafficking. Trends Cell Biol. 2009, 19, 147-155. [CrossRef] [PubMed]

23. Cattaneo, E.; Zuccato, C.; Tartari, M. Normal huntingtin function: An alternative approach to Huntington's disease. Nat. Rev. Neurosci. 2005, 6, 919-930. [CrossRef] [PubMed]

24. Gauthier, L.R.; Charrin, B.C.; Borrell-Pages, M.; Dompierre, J.P.; Rangone, H.; Cordelieres, F.P.; De Mey, J.; MacDonald, M.E.; Lessmann, V.; Humbert, S.; et al. Huntingtin controls neurotrophic support and survival of neurons by enhancing BDNF vesicular transport along microtubules. Cell 2004, 118, 127-138. [CrossRef] [PubMed]

25. Nasir, J.; Floresco, S.B.; O’Kusky, J.R.; Diewert, V.M.; Richman, J.M.; Zeisler, J.; Borowski, A.; Marth, J.D.; Phillips, A.G.; Hayden, M.R. Targeted disruption of the Huntington's disease gene results in embryonic lethality and behavioral and morphological changes in heterozygotes. Cell 1995, 81, 811-823. [CrossRef]

26. Bonini, N.M.; Fortini, M.E. Human neurodegenerative disease modeling using Drosophila. Annu. Rev. Neurosci. 2003, 26, 627-656. [CrossRef] [PubMed]

27. Matos, C.A.; Carmona, V.; Vijayakumar, U.G.; Lopes, S.; Albuquerque, P.; Conceicao, M.; Nobre, R.J.; Nobrega, C.; de Almeida, L.P. Gene Therapies for Polyglutamine Diseases. Adv. Exp. Med. Biol. 2018, 1049, 395-438. [PubMed]

28. Paulson, H.L.; Bonini, N.M.; Roth, K.A. Polyglutamine disease and neuronal cell death. Proc. Natl. Acad. Sci. USA 2000, 97, 12957-12958. [CrossRef] [PubMed]

29. Brinkman, R.R.; Mezei, M.M.; Theilmann, J.; Almqvist, E.; Hayden, M.R. The likelihood of being affected with Huntington disease by a particular age, for a specific CAG size. Am. J. Hum. Genet. 1997, 60, 1202-1210. [PubMed] 
30. Kremer, B.; Goldberg, P.; Andrew, S.E.; Theilmann, J.; Telenius, H.; Zeisler, J.; Squitieri, F.; Lin, B.; Bassett, A.; Almqvist, E.; et al. A worldwide study of the Huntington's disease mutation. The sensitivity and specificity of measuring CAG repeats. N. Engl. J. Med. 1994, 330, 1401-1406. [CrossRef] [PubMed]

31. Rubinsztein, D.C.; Leggo, J.; Coles, R.; Almqvist, E.; Biancalana, V.; Cassiman, J.J.; Chotai, K.; Connarty, M.; Crauford, D.; Curtis, A.; et al. Phenotypic characterization of individuals with 30-40 CAG repeats in the Huntington disease (HD) gene reveals HD cases with 36 repeats and apparently normal elderly individuals with 36-39 repeats. Am. J. Hum. Genet. 1996, 59, 16-22. [PubMed]

32. Mirkin, S.M. Expandable DNA repeats and human disease. Nature 2007, 447, 932-940. [CrossRef] [PubMed]

33. Gunawardena, S.; Her, L.S.; Brusch, R.G.; Laymon, R.A.; Niesman, I.R.; Gordesky-Gold, B.; Sintasath, L.; Bonini, N.M.; Goldstein, L.S. Disruption of axonal transport by loss of huntingtin or expression of pathogenic polyQ proteins in Drosophila. Neuron 2003, 40, 25-40. [CrossRef]

34. Tang, T.S.; Slow, E.; Lupu, V.; Stavrovskaya, I.G.; Sugimori, M.; Llinas, R.; Kristal, B.S.; Hayden, M.R.; Bezprozvanny, I. Disturbed $\mathrm{Ca}^{2+}$ signaling and apoptosis of medium spiny neurons in Huntington's disease. Proc. Natl. Acad. Sci. USA 2005, 102, 2602-2607. [CrossRef] [PubMed]

35. Lee, J.; Hwang, Y.J.; Kim, K.Y.; Kowall, N.W.; Ryu, H. Epigenetic mechanisms of neurodegeneration in Huntington's disease. Neurotherapeutics 2013, 10, 664-676. [CrossRef] [PubMed]

36. Huntington, G. On Chorea. Med. Surg. Rep. 1872, 26, 317-321.

37. Wexler, A.; Wild, E.J.; Tabrizi, S.J. George Huntington: A legacy of inquiry, empathy and hope. Brain 2016, 139, 2326-2333. [CrossRef] [PubMed]

38. Rawlins, M.D.; Wexler, N.S.; Wexler, A.R.; Tabrizi, S.J.; Douglas, I.; Evans, S.J.; Smeeth, L. The Prevalence of Huntington's Disease. Neuroepidemiology 2016, 46, 144-153. [CrossRef] [PubMed]

39. Haddad, M.S.; Cummings, J.L. Huntington's disease. Psychiatr. Clin. N. Am. 1997, 20, 791-807. [CrossRef]

40. Vonsattel, J.P.; DiFiglia, M. Huntington disease. J. Neuropathol. Exp. Neurol. 1998, 57, 369-384. [CrossRef] [PubMed]

41. Bano, D.; Zanetti, F.; Mende, Y.; Nicotera, P. Neurodegenerative processes in Huntington's disease. Cell Death Dis. 2011, 2, e228. [CrossRef] [PubMed]

42. Ehrlich, M.E. Huntington's disease and the striatal medium spiny neuron: Cell-autonomous and non-cell-autonomous mechanisms of disease. Neurotherapeutics 2012, 9, 270-284. [CrossRef] [PubMed]

43. Reiner, A.; Albin, R.L.; Anderson, K.D.; D'Amato, C.J.; Penney, J.B.; Young, A.B. Differential loss of striatal projection neurons in Huntington disease. Proc. Natl. Acad. Sci. USA 1988, 85, 5733-5737. [CrossRef] [PubMed]

44. Reiner, A.; Deng, Y.P. Disrupted striatal neuron inputs and outputs in Huntington's disease. CNS Neurosci. Ther. 2018, 24, 250-280. [CrossRef] [PubMed]

45. Rosas-Arellano, A.; Tejeda-Guzman, C.; Lorca-Ponce, E.; Palma-Tirado, L.; Mantellero, C.A.; Rojas, P.; Missirlis, F.; Castro, M.A. Huntington's disease leads to decrease of GABA-A tonic subunits in the D2 neostriatal pathway and their relocalization into the synaptic cleft. Neurobiol. Dis. 2018, 110, 142-153. [CrossRef] [PubMed]

46. Tejeda-Guzman, C.; Rosas-Arellano, A.; Kroll, T.; Webb, S.M.; Barajas-Aceves, M.; Osorio, B.; Missirlis, F. Biogenesis of zinc storage granules in Drosophila melanogaster. J. Exp. Biol. 2018, 221, jeb.168419. [CrossRef] [PubMed]

47. Crook, Z.R.; Housman, D.E. Dysregulation of dopamine receptor D2 as a sensitive measure for Huntington disease pathology in model mice. Proc. Natl. Acad. Sci. USA 2012, 109, 7487-7492. [CrossRef] [PubMed]

48. Cepeda, C.; Hurst, R.S.; Calvert, C.R.; Hernandez-Echeagaray, E.; Nguyen, O.K.; Jocoy, E.; Christian, L.J.; Ariano, M.A.; Levine, M.S. Transient and progressive electrophysiological alterations in the corticostriatal pathway in a mouse model of Huntington's disease. J. Neurosci. 2003, 23, 961-969. [CrossRef] [PubMed]

49. Du, Z.; Tertrais, M.; Courtand, G.; Leste-Lasserre, T.; Cardoit, L.; Masmejean, F.; Halgand, C.; Cho, Y.H.; Garret, M. Differential Alteration in Expression of Striatal GABAAR Subunits in Mouse Models of Huntington's Disease. Front. Mol. Neurosci. 2017, 10, 198. [CrossRef] [PubMed]

50. Ellison, D.W.; Beal, M.F.; Mazurek, M.F.; Malloy, J.R.; Bird, E.D.; Martin, J.B. Amino acid neurotransmitter abnormalities in Huntington's disease and the quinolinic acid animal model of Huntington's disease. Brain 1987, 110, 1657-1673. [CrossRef] [PubMed] 
51. Spokes, E.G.; Garrett, N.J.; Iversen, L.L. Differential effects of agonal status on measurements of GABA and glutamate decarboxylase in human post-mortem brain tissue from control and Huntington's chorea subjects. J. Neurochem. 1979, 33, 773-778. [CrossRef] [PubMed]

52. Kumar, U.; Heer, M.; Somvanshi, R.K. Regional and subcellular distribution of GABA $\mathrm{C}_{\mathrm{C}} \mathrm{3}$ receptor in brain of R6/2 mouse model of Huntington's disease. Neurosci. Lett. 2017, 640, 81-87. [CrossRef] [PubMed]

53. Rosas-Arellano, A.; Estrada-Mondragon, A.; Mantellero, C.A.; Tejeda-Guzman, C.; Castro, M.A. The adjustment of gamma-aminobutyric acidA tonic subunits in Huntington's disease: From transcription to translation to synaptic levels into the neostriatum. Neural Regen. Res. 2018, 13, 584-590. [CrossRef] [PubMed]

54. Kaplan, S.V.; Limbocker, R.A.; Levant, B.; Johnson, M.A. Regional Differences in Dopamine Release in the R6/2 Mouse Caudate Putamen. Electroanalysis 2018, 30, 1066-1072. [CrossRef] [PubMed]

55. Rebec, G.V. Corticostriatal network dysfunction in Huntington's disease: Deficits in neural processing, glutamate transport, and ascorbate release. CNS Neurosci. Ther. 2018, 24, 281-291. [CrossRef] [PubMed]

56. Kawaguchi, Y. Neostriatal cell subtypes and their functional roles. Neurosci. Res. 1997, 27, 1-8. [CrossRef]

57. Rosas-Arellano, A.; Machuca-Parra, A.I.; Reyes-Haro, D.; Miledi, R.; Martinez-Torres, A. Expression of GABArho receptors in the neostriatum: Localization in aspiny, medium spiny neurons and GFAP-positive cells. J. Neurochem. 2012, 122, 900-910. [CrossRef] [PubMed]

58. Kawaguchi, Y.; Wilson, C.J.; Emson, P.C. Intracellular recording of identified neostriatal patch and matrix spiny cells in a slice preparation preserving cortical inputs. J. Neurophysiol. 1989, 62, 1052-1068. [CrossRef] [PubMed]

59. Kemp, J.M.; Powell, T.P. The connexions of the striatum and globus pallidus: Synthesis and speculation. Philos. Trans. R. Soc. Lond. B Biol. Sci. 1971, 262, 441-457. [CrossRef] [PubMed]

60. Alexander, G.E.; Crutcher, M.D. Functional architecture of basal ganglia circuits: Neural substrates of parallel processing. Trends Neurosci. 1990, 13, 266-271. [CrossRef]

61. Doig, N.M.; Moss, J.; Bolam, J.P. Cortical and thalamic innervation of direct and indirect pathway medium-sized spiny neurons in mouse striatum. J. Neurosci. 2010, 30, 14610-14618. [CrossRef] [PubMed]

62. Gerfen, C.R.; Engber, T.M.; Mahan, L.C.; Susel, Z.; Chase, T.N.; Monsma, F.J., Jr.; Sibley, D.R. D1 and D2 dopamine receptor-regulated gene expression of striatonigral and striatopallidal neurons. Science 1990, 250, 1429-1432. [CrossRef] [PubMed]

63. Surmeier, D.J.; Reiner, A.; Levine, M.S.; Ariano, M.A. Are neostriatal dopamine receptors co-localized? Trends Neurosci. 1993, 16, 299-305. [CrossRef]

64. Gerfen, C.R. The neostriatal mosaic: Multiple levels of compartmental organization. Trends Neurosci. 1992, 15, 133-139. [CrossRef]

65. Albin, R.L.; Young, A.B.; Penney, J.B. The functional anatomy of basal ganglia disorders. Trends Neurosci. 1989, 12, 366-375. [CrossRef]

66. Strausfeld, N.J.; Hirth, F. Deep homology of arthropod central complex and vertebrate basal ganglia. Science 2013, 340, 157-161. [CrossRef] [PubMed]

67. Martin-Pena, A.; Acebes, A.; Rodriguez, J.R.; Chevalier, V.; Casas-Tinto, S.; Triphan, T.; Strauss, R.; Ferrus, A. Cell types and coincident synapses in the ellipsoid body of Drosophila. Eur. J. Neurosci. 2014, 39, 1586-1601. [CrossRef] [PubMed]

68. Renn, S.C.; Armstrong, J.D.; Yang, M.; Wang, Z.; An, X.; Kaiser, K.; Taghert, P.H. Genetic analysis of the Drosophila ellipsoid body neuropil: Organization and development of the central complex. J. Neurobiol. 1999, 41, 189-207. [CrossRef]

69. Strauss, R.; Heisenberg, M. A higher control center of locomotor behavior in the Drosophila brain. J. Neurosci. 1993, 13, 1852-1861. [CrossRef] [PubMed]

70. Martin, J.R.; Raabe, T.; Heisenberg, M. Central complex substructures are required for the maintenance of locomotor activity in Drosophila melanogaster. J. Comp. Physiol. A 1999, 185, 277-288. [CrossRef] [PubMed]

71. Ilius, M.; Wolf, R.; Heisenberg, M. The central complex of Drosophila melanogaster is involved in flight control: Studies on mutants and mosaics of the gene ellipsoid body open. J. Neurogenet. 2007, 21, 321-338. [CrossRef] [PubMed] 
72. Yang, J.S.; Awasaki, T.; Yu, H.H.; He, Y.; Ding, P.; Kao, J.C.; Lee, T. Diverse neuronal lineages make stereotyped contributions to the Drosophila locomotor control center, the central complex. J. Comp. Neurol. 2013, 521, 2645-2662. [CrossRef] [PubMed]

73. Young, J.M.; Armstrong, J.D. Structure of the adult central complex in Drosophila: Organization of distinct neuronal subsets. J. Comp. Neurol. 2010, 518, 1500-1524. [CrossRef] [PubMed]

74. Wolff, T.; Iyer, N.A.; Rubin, G.M. Neuroarchitecture and neuroanatomy of the Drosophila central complex: A GAL4-based dissection of protocerebral bridge neurons and circuits. J. Comp. Neurol. 2015, 523, 997-1037. [CrossRef] [PubMed]

75. Andrade, M.A.; Bork, P. HEAT repeats in the Huntington's disease protein. Nat. Genet. 1995, 11, 115-116. [CrossRef] [PubMed]

76. Dietz, K.N.; Di Stefano, L.; Maher, R.C.; Zhu, H.; Macdonald, M.E.; Gusella, J.F.; Walker, J.A. The Drosophila Huntington's disease gene ortholog dhtt influences chromatin regulation during development. Hum. Mol. Genet. 2015, 24, 330-345. [CrossRef] [PubMed]

77. Clark, A.G.; Eisen, M.B.; Smith, D.R.; Bergman, C.M.; Oliver, B.; Markow, T.A.; Kaufman, T.C.; Kellis, M.; Gelbart, W.; Iyer, V.N.; et al. Evolution of genes and genomes on the Drosophila phylogeny. Nature 2007, 450, 203-218. [PubMed]

78. Zala, D.; Hinckelmann, M.V.; Saudou, F. Huntingtin's function in axonal transport is conserved in Drosophila melanogaster. PLoS ONE 2013, 8, e60162. [CrossRef] [PubMed]

79. Lee, W.C.; Yoshihara, M.; Littleton, J.T. Cytoplasmic aggregates trap polyglutamine-containing proteins and block axonal transport in a Drosophila model of Huntington's disease. Proc. Natl. Acad. Sci. USA 2004, 101, 3224-3229. [CrossRef] [PubMed]

80. White, J.A., 2nd; Anderson, E.; Zimmerman, K.; Zheng, K.H.; Rouhani, R.; Gunawardena, S. Huntingtin differentially regulates the axonal transport of a sub-set of Rab-containing vesicles in vivo. Hum. Mol. Genet. 2015, 24, 7182-7195. [CrossRef] [PubMed]

81. Kim, M.W.; Chelliah, Y.; Kim, S.W.; Otwinowski, Z.; Bezprozvanny, I. Secondary structure of Huntingtin amino-terminal region. Structure 2009, 17, 1205-1212. [CrossRef] [PubMed]

82. Keros, T.; Borovecki, F.; Jemersic, L.; Konjevic, D.; Roic, B.; Balatinec, J. The centenary progress of molecular genetics. A 100th anniversary of T. H. Morgan's discoveries. Coll. Antropol. 2010, 34, 1167-1174. [PubMed]

83. Jennings, B.H. Drosophila a versatile model in biology and medicine. Mater. Today 2011, 14, $190-195$. [CrossRef]

84. Reiter, L.T.; Potocki, L.; Chien, S.; Gribskov, M.; Bier, E. A systematic analysis of human disease-associated gene sequences in Drosophila melanogaster. Genome Res. 2001, 11, 1114-1125. [CrossRef] [PubMed]

85. Morgan, T.H. Sex Limited Inheritance in Drosophila. Science 1910, 32, 120-122. [CrossRef] [PubMed]

86. Muller, H.J. Artificial Transmutation of the Gene. Science 1927, 66, 84-87. [CrossRef] [PubMed]

87. Nusslein-Volhard, C.; Wieschaus, E. Mutations affecting segment number and polarity in Drosophila. Nature 1980, 287, 795-801. [CrossRef] [PubMed]

88. Lemaitre, B.; Nicolas, E.; Michaut, L.; Reichhart, J.M.; Hoffmann, J.A. The dorsoventral regulatory gene cassette spatzle/Toll/cactus controls the potent antifungal response in Drosophila adults. Cell 1996, 86, 973-983. [CrossRef]

89. Zehring, W.A.; Wheeler, D.A.; Reddy, P.; Konopka, R.J.; Kyriacou, C.P.; Rosbash, M.; Hall, J.C. P-element transformation with period locus DNA restores rhythmicity to mutant, arrhythmic Drosophila melanogaster. Cell 1984, 39, 369-376. [CrossRef]

90. Shih, J.; Hodge, R.; Andrade-Navarro, M.A. Comparison of inter- and intraspecies variation in humans and fruit flies. Genom. Data 2015, 3, 49-54. [CrossRef] [PubMed]

91. Kosmidis, S.; Botella, J.A.; Mandilaras, K.; Schneuwly, S.; Skoulakis, E.M.; Rouault, T.A.; Missirlis, F. Ferritin overexpression in Drosophila glia leads to iron deposition in the optic lobes and late-onset behavioral defects. Neurobiol. Dis. 2011, 43, 213-219. [CrossRef] [PubMed]

92. Rosas-Arellano, A.; Vasquez-Procopio, J.; Gambis, A.; Blowes, L.M.; Steller, H.; Mollereau, B.; Missirlis, F. Ferritin Assembly in Enterocytes of Drosophila melanogaster. Int. J. Mol. Sci. 2016, 17, 27. [CrossRef] [PubMed] 
93. Marsh, J.L.; Thompson, L.M. Can flies help humans treat neurodegenerative diseases? Bioessays 2004, 26, 485-496. [CrossRef] [PubMed]

94. Wang, C.E.; Tydlacka, S.; Orr, A.L.; Yang, S.H.; Graham, R.K.; Hayden, M.R.; Li, S.; Chan, A.W.; Li, X.J. Accumulation of N-terminal mutant huntingtin in mouse and monkey models implicated as a pathogenic mechanism in Huntington's disease. Hum. Mol. Genet. 2008, 17, 2738-2751. [CrossRef] [PubMed]

95. El-Daher, M.T.; Hangen, E.; Bruyere, J.; Poizat, G.; Al-Ramahi, I.; Pardo, R.; Bourg, N.; Souquere, S.; Mayet, C.; Pierron, G.; et al. Huntingtin proteolysis releases non-polyQ fragments that cause toxicity through dynamin 1 dysregulation. EMBO J. 2015, 34, 2255-2271. [CrossRef] [PubMed]

96. Gonzales, E.D.; Tanenhaus, A.K.; Zhang, J.; Chaffee, R.P.; Yin, J.C. Early-onset sleep defects in Drosophila models of Huntington's disease reflect alterations of PKA/CREB signaling. Hum. Mol. Genet. 2016, 25, 837-852. [CrossRef] [PubMed]

97. Li, W.; Ohlmeyer, J.T.; Lane, M.E.; Kalderon, D. Function of protein kinase A in hedgehog signal transduction and Drosophila imaginal disc development. Cell 1995, 80, 553-562. [CrossRef]

98. Singh, M.D.; Raj, K.; Sarkar, S. Drosophila Myc, a novel modifier suppresses the poly(Q) toxicity by modulating the level of CREB binding protein and histone acetylation. Neurobiol. Dis. 2014, 63, 48-61. [CrossRef] [PubMed]

99. Raj, K.; Sarkar, S. Transactivation Domain of Human c-Myc Is Essential to Alleviate Poly(Q)-Mediated Neurotoxicity in Drosophila Disease Models. J. Mol. Neurosci. 2017, 62, 55-66. [CrossRef] [PubMed]

100. Steffan, J.S.; Bodai, L.; Pallos, J.; Poelman, M.; McCampbell, A.; Apostol, B.L.; Kazantsev, A.; Schmidt, E.; Zhu, Y.Z.; Greenwald, M.; et al. Histone deacetylase inhibitors arrest polyglutamine-dependent neurodegeneration in Drosophila. Nature 2001, 413, 739-743. [CrossRef] [PubMed]

101. Bodai, L.; Pallos, J.; Thompson, L.M.; Marsh, J.L. Pcaf modulates polyglutamine pathology in a Drosophila model of Huntington's disease. Neurodegener. Dis. 2012, 9, 104-106. [CrossRef] [PubMed]

102. Kazemi-Esfarjani, P.; Benzer, S. Genetic suppression of polyglutamine toxicity in Drosophila. Science 2000, 287, 1837-1840. [CrossRef] [PubMed]

103. Rui, Y.N.; Xu, Z.; Patel, B.; Chen, Z.; Chen, D.; Tito, A.; David, G.; Sun, Y.; Stimming, E.F.; Bellen, H.J.; et al. Huntingtin functions as a scaffold for selective macroautophagy. Nat. Cell Biol. 2015, 17, 262-275. [CrossRef] [PubMed]

104. Mizushima, N.; Komatsu, M. Autophagy: Renovation of cells and tissues. Cell 2011, 147, 728-741. [CrossRef] [PubMed]

105. Pecho-Vrieseling, E.; Rieker, C.; Fuchs, S.; Bleckmann, D.; Esposito, M.S.; Botta, P.; Goldstein, C.; Bernhard, M.; Galimberti, I.; Muller, M.; et al. Transneuronal propagation of mutant huntingtin contributes to non-cell autonomous pathology in neurons. Nat. Neurosci. 2014, 17, 1064-1072. [CrossRef] [PubMed]

106. Weiss, K.R.; Kimura, Y.; Lee, W.C.; Littleton, J.T. Huntingtin aggregation kinetics and their pathological role in a Drosophila Huntington's disease model. Genetics 2012, 190, 581-600. [CrossRef] [PubMed]

107. Babcock, D.T.; Ganetzky, B. Transcellular spreading of huntingtin aggregates in the Drosophila brain. Proc. Natl. Acad. Sci. USA 2015, 112, E5427-E5433. [CrossRef] [PubMed]

108. Caesar, I.; Jonson, M.; Nilsson, K.P.; Thor, S.; Hammarstrom, P. Curcumin promotes A-beta fibrillation and reduces neurotoxicity in transgenic Drosophila. PLoS ONE 2012, 7, e31424. [CrossRef] [PubMed]

109. Marsh, J.L.; Walker, H.; Theisen, H.; Zhu, Y.Z.; Fielder, T.; Purcell, J.; Thompson, L.M. Expanded polyglutamine peptides alone are intrinsically cytotoxic and cause neurodegeneration in Drosophila. Hum. Mol. Genet. 2000, 9, 13-25. [CrossRef] [PubMed]

110. Chongtham, A.; Agrawal, N. Curcumin modulates cell death and is protective in Huntington's disease model. Sci. Rep. 2016, 6, 18736. [CrossRef] [PubMed]

111. Song, W.; Smith, M.R.; Syed, A.; Lukacsovich, T.; Barbaro, B.A.; Purcell, J.; Bornemann, D.J.; Burke, J.; Marsh, J.L. Morphometric analysis of Huntington's disease neurodegeneration in Drosophila. Methods Mol. Biol. 2013, 1017, 41-57. [PubMed]

112. Joyner, P.M.; Matheke, R.M.; Smith, L.M.; Cichewicz, R.H. Probing the metabolic aberrations underlying mutant huntingtin toxicity in yeast and assessing their degree of preservation in humans and mice. J. Proteome Res. 2010, 9, 404-412. [CrossRef] [PubMed] 
113. Singh, V.; Sharma, R.K.; Athilingam, T.; Sinha, P.; Sinha, N.; Thakur, A.K. NMR Spectroscopy-based Metabolomics of Drosophila Model of Huntington's Disease Suggests Altered Cell Energetics. J. Proteome Res. 2017, 16, 3863-3872. [CrossRef] [PubMed]

114. Zhang, J.; Schulze, K.L.; Hiesinger, P.R.; Suyama, K.; Wang, S.; Fish, M.; Acar, M.; Hoskins, R.A.; Bellen, H.J.; Scott, M.P. Thirty-one flavors of Drosophila rab proteins. Genetics 2007, 176, 1307-1322. [CrossRef] [PubMed]

115. Stenmark, H.; Olkkonen, V.M. The Rab GTPase family. Genome Biol. 2001, 2, REVIEWS3007. [CrossRef] [PubMed]

116. Ravikumar, B.; Imarisio, S.; Sarkar, S.; O’Kane, C.J.; Rubinsztein, D.C. Rab5 modulates aggregation and toxicity of mutant huntingtin through macroautophagy in cell and fly models of Huntington disease. J. Cell Sci. 2008, 121, 1649-1660. [CrossRef] [PubMed]

117. Parievsky, A.; Moore, C.; Kamdjou, T.; Cepeda, C.; Meshul, C.K.; Levine, M.S. Differential electrophysiological and morphological alterations of thalamostriatal and corticostriatal projections in the R6/2 mouse model of Huntington's disease. Neurobiol. Dis. 2017, 108, 29-44. [CrossRef] [PubMed]

118. Akbergenova, Y.; Littleton, J.T. Pathogenic Huntington Alters BMP Signaling and Synaptic Growth through Local Disruptions of Endosomal Compartments. J. Neurosci. 2017, 37, 3425-3439. [CrossRef] [PubMed]

119. Riley, B.E.; Orr, H.T. Polyglutamine neurodegenerative diseases and regulation of transcription: Assembling the puzzle. Genes Dev. 2006, 20, 2183-2192. [CrossRef] [PubMed]

120. Sun, L.; Chang, J.; Kirchhoff, S.R.; Knowlton, A.A. Activation of HSF and selective increase in heat-shock proteins by acute dexamethasone treatment. Am. J. Physiol. Heart Circ. Physiol. 2000, 278, H1091-H1097. [CrossRef] [PubMed]

121. Maheshwari, M.; Bhutani, S.; Das, A.; Mukherjee, R.; Sharma, A.; Kino, Y.; Nukina, N.; Jana, N.R. Dexamethasone induces heat shock response and slows down disease progression in mouse and fly models of Huntington's disease. Hum. Mol. Genet. 2014, 23, 2737-2751. [CrossRef] [PubMed]

122. Schmelzle, T.; Hall, M.N. TOR, a central controller of cell growth. Cell 2000, 103, 253-262. [CrossRef]

123. Ravikumar, B.; Vacher, C.; Berger, Z.; Davies, J.E.; Luo, S.; Oroz, L.G.; Scaravilli, F.; Easton, D.F.; Duden, R.; O'Kane, C.J.; et al. Inhibition of mTOR induces autophagy and reduces toxicity of polyglutamine expansions in fly and mouse models of Huntington disease. Nat. Genet. 2004, 36, 585-595. [CrossRef] [PubMed]

124. Melkani, G.C.; Trujillo, A.S.; Ramos, R.; Bodmer, R.; Bernstein, S.I.; Ocorr, K. Huntington's disease induced cardiac amyloidosis is reversed by modulating protein folding and oxidative stress pathways in the Drosophila heart. PLoS Genet. 2013, 9, e1004024. [CrossRef] [PubMed]

125. Xiao, G.; Fan, Q.; Wang, X.; Zhou, B. Huntington disease arises from a combinatory toxicity of polyglutamine and copper binding. Proc. Natl. Acad. Sci. USA 2013, 110, 14995-15000. [CrossRef] [PubMed]

126. Mason, R.P.; Casu, M.; Butler, N.; Breda, C.; Campesan, S.; Clapp, J.; Green, E.W.; Dhulkhed, D.; Kyriacou, C.P.; Giorgini, F. Glutathione peroxidase activity is neuroprotective in models of Huntington's disease. Nat. Genet. 2013, 45, 1249-1254. [CrossRef] [PubMed]

127. Campesan, S.; Green, E.W.; Breda, C.; Sathyasaikumar, K.V.; Muchowski, P.J.; Schwarcz, R.; Kyriacou, C.P.; Giorgini, F. The kynurenine pathway modulates neurodegeneration in a Drosophila model of Huntington's disease. Curr. Biol. 2011, 21, 961-966. [CrossRef] [PubMed]

128. Beltran, F.A.; Acuna, A.I.; Miro, M.P.; Angulo, C.; Concha, I.I.; Castro, M.A. Ascorbic acid-dependent GLUT3 inhibition is a critical step for switching neuronal metabolism. J. Cell. Physiol. 2011, 226, 3286-3294. [CrossRef] [PubMed]

129. Khakh, B.S.; Beaumont, V.; Cachope, R.; Munoz-Sanjuan, I.; Goldman, S.A.; Grantyn, R. Unravelling and Exploiting Astrocyte Dysfunction in Huntington's Disease. Trends Neurosci. 2017, 40, 422-437. [CrossRef] [PubMed]

130. Vagner, T.; Dvorzhak, A.; Wojtowicz, A.M.; Harms, C.; Grantyn, R. Systemic application of AAV vectors targeting GFAP-expressing astrocytes in Z-Q175-KI Huntington's disease mice. Mol. Cell. Neurosci. 2016, 77, 76-86. [CrossRef] [PubMed]

131. Yeh, P.A.; Liu, Y.H.; Chu, W.C.; Liu, J.Y.; Sun, Y.H. Glial Expression of Disease-associated Poly-glutamine Proteins Impairs the Blood-Brain Barrier in Drosophila. Hum. Mol. Genet. 2018, 27, 2546-2562. [CrossRef] [PubMed] 
132. Lievens, J.C.; Iche, M.; Laval, M.; Faivre-Sarrailh, C.; Birman, S. AKT-sensitive or insensitive pathways of toxicity in glial cells and neurons in Drosophila models of Huntington's disease. Hum. Mol. Genet. 2008, 17, 882-894. [CrossRef] [PubMed]

133. Tamura, T.; Sone, M.; Yamashita, M.; Wanker, E.E.; Okazawa, H. Glial cell lineage expression of mutant ataxin-1 and huntingtin induces developmental and late-onset neuronal pathologies in Drosophila models. PLOS ONE 2009, 4, e4262. [CrossRef] [PubMed]

134. Besson, M.T.; Dupont, P.; Fridell, Y.W.; Lievens, J.C. Increased energy metabolism rescues glia-induced pathology in a Drosophila model of Huntington's disease. Hum. Mol. Genet. 2010, 19, 3372-3382. [CrossRef] [PubMed]

135. Crotti, A.; Benner, C.; Kerman, B.E.; Gosselin, D.; Lagier-Tourenne, C.; Zuccato, C.; Cattaneo, E.; Gage, F.H.; Cleveland, D.W.; Glass, C.K. Mutant Huntingtin promotes autonomous microglia activation via myeloid lineage-determining factors. Nat. Neurosci. 2014, 17, 513-521. [CrossRef] [PubMed]

136. Pearce, M.M.; Spartz, E.J.; Hong, W.; Luo, L.; Kopito, R.R. Prion-like transmission of neuronal huntingtin aggregates to phagocytic glia in the Drosophila brain. Nat. Commun. 2015, 6, 6768. [CrossRef] [PubMed]

(C) 2018 by the authors. Licensee MDPI, Basel, Switzerland. This article is an open access article distributed under the terms and conditions of the Creative Commons Attribution (CC BY) license (http:/ / creativecommons.org/licenses/by/4.0/). 